\title{
1. Modeling the impact of racial and ethnic disparities on COVID-19 2 epidemic dynamics
}

${ }_{3}$ Kevin C. Ma ${ }^{1}$, Tigist F. Menkir ${ }^{2}$, Stephen Kissler ${ }^{1}$, Yonatan H. Grad ${ }^{1,3}$, Marc Lipsitch ${ }^{1,2^{*}}$

$4{ }^{1}$ Department of Immunology and Infectious Diseases, Harvard T.H. Chan School of Public Health,

5 Boston, USA

$6{ }^{2}$ Center for Communicable Disease Dynamics, Department of Epidemiology, Harvard T.H. Chan

7 School of Public Health, Boston, USA

$8{ }^{3}$ Division of Infectious Diseases, Brigham and Women's Hospital and Harvard Medical School, Boston, 9 USA

*Corresponding author. Email: mlipsitc@hsph.harvard.edu 
medRxiv preprint doi: https://doi.org/10.1101/2021.01.15.21249881; this version posted May 1, 2021. The copyright holder for this preprint (which was not certified by peer review) is the author/funder, who has granted medRxiv a license to display the preprint in perpetuity. It is made available under a CC-BY-NC-ND 4.0 International license.

\section{Abstract}

The impact of variable infection risk by race and ethnicity on the dynamics of SARS-CoV-2 spread is largely unknown. Here, we fit structured compartmental models to seroprevalence data from New York State and analyze how herd immunity thresholds (HITs), final sizes, and epidemic risk changes across groups. A simple model where interactions occur proportionally to contact rates reduced the HIT, but more realistic models of preferential mixing within groups increased the threshold toward the value observed in homogeneous populations. Across all models, the burden of infection fell disproportionately on minority populations: in a model fit to Long Island serosurvey and census data, $81 \%$ of Hispanics or Latinos were infected when the HIT was reached compared to $34 \%$ of nonHispanic whites. Our findings, which are meant to be illustrative and not best estimates, demonstrate how racial and ethnic disparities can impact epidemic trajectories and result in unequal distributions of SARS-CoV-2 infection. 
medRxiv preprint doi: https://doi.org/10.1101/2021.01.15.21249881; this version posted May 1, 2021. The copyright holder for this preprint (which was not certified by peer review) is the author/funder, who has granted medRxiv a license to display the preprint in perpetuity. It is made available under a CC-BY-NC-ND 4.0 International license .

\section{Introduction}

The dynamics of SARS-CoV-2 spread are influenced by population heterogeneity. This is especially true for herd immunity, which occurs when susceptible individuals in a population are indirectly protected from infection due to immunity in others. The herd immunity threshold (HIT) is the fraction of the population that is non-susceptible when an unmitigated epidemic reaches its peak, and estimating the HIT for SARS-CoV-2 is important for forecasting the harm associated with letting the epidemic spread in the absence of interventions [1]. A population that has reached the HIT is protected from a new epidemic occurring, until births or waning immunity reduce the proportion nonsusceptible below the HIT, but existing cases will still lead to some onward transmission as the epidemic declines and can often result in a final epidemic size that exceeds the HIT. In a population with homogeneous mixing, the HIT is $1-1 / R_{0}$, where $R_{0}$ is the basic reproduction number; this translates to an HIT of $67 \%$ using an $R_{0}$ of 3 .

However, population homogeneity is an unrealistic assumption, and models incorporating heterogeneity in social exposure and infection susceptibility (defined as the probability of infection given exposure) generally result in lowered HITs [2-6]. The key idea behind these models is that subpopulations important for epidemic spread (i.e., those with substantially increased susceptibility or exposure) become infected - and thus develop immunity - early on in an epidemic's course. Herd immunity for the population overall is then achieved earlier because once these individuals are no longer susceptible to infection, further epidemic spread is slowed.

Importantly, these models also imply that in locations where SARS-CoV-2 has spread, there may be demographic sub-populations with particularly high cumulative incidences of infection due to increased exposure, susceptibility, or both. Seroprevalence studies - which characterize past exposure by identifying SARS-CoV-2 antibodies - can identify these sub-populations and are more reliable and unbiased than case data, which suffer from under-reporting and other biases [7]. Identifying and building structured models with these groups in mind is important for understanding how variation in exposure or susceptibility and social disparities are interconnected. These models are also useful for designing interventions that can both reduce disparities and disrupt overall transmission by focusing efforts on groups most affected by high transmission rates [8, 9]. Transmission models in this space have incorporated subpopulation structure by focusing primarily on accounting for variation in susceptibility and exposure by age [3, 10, 11]. Supporting this approach, susceptibility to infection, contact rates, and cumulative incidence in some locations all appear to vary by age 
medRxiv preprint doi: https://doi.org/10.1101/2021.01.15.21249881; this version posted May 1, 2021. The copyright holder for this preprint (which was not certified by peer review) is the author/funder, who has granted medRxiv a license to display the preprint in perpetuity.

It is made available under a CC-BY-NC-ND 4.0 International license .

[10, 12]. Nonetheless, serosurveys in Belgium, Spain, Iran, New York City, Brazil, and other places exhibit relatively low variation in seropositivity by age [13-17], indicating additional factors that govern transmission spread.

Substantial racial and ethnic disparities in infection rates, hospitalizations, and deaths have been characterized across the US [18-24], but it is unclear how these heterogeneities in risk are expected to change over time, and what implications - if any - they have on overall epidemic dynamics. Here, we aim to address these questions by fitting compartmental SEIR transmission models structured by race and ethnicity to seroprevalence data from New York City and Long Island [16]. We focus primarily on building and analyzing variable exposure models because observed disparities in infection rates in US cities are strongly attributable to differences in mobility and exposure [25-27]. Because of the challenges in acquiring racial and ethnic COVID-19 data [28], including social contact data that can be used in transmission models, we analyze a range of model structures that are compatible with the data and assess how these assumptions affect estimates of HITs, final epidemic sizes, and longitudinal trends in risk across groups. These results highlight the importance of developing socially-informed COVID-19 transmission models that incorporate patterns of epidemic spread across racial and ethnic groups.

\section{Methods}

\section{SEIR model}

We initially modeled transmission dynamics in a homogeneous population using an SEIR compartmental SARS-CoV-2 infection model:

$$
\frac{d S}{d t}=-\beta I S
$$

$$
\frac{d E}{d t}=\beta I S-r E
$$

$$
\frac{d I}{d t}=r E-\gamma I
$$

$$
\frac{d R}{d t}=\gamma I
$$

where $S, E, I, R$ refer to the number of people in susceptible, latently infected, infectious, and recovered compartments respectively. Given a mean incubation period and mean serial interval of 5 days as suggested by empirical studies [29, 30], we set the mean latent period $1 / r$ to be 3 days to allow 
for pre-symptomatic transmission and the mean infectious period $1 / \gamma$ to be 4 days to coincide with the observed serial interval. The per capita transmission rate is given by $\beta=R_{0} \gamma / N$, where $N$ is the total number of people in the population.

We extended this model to incorporate multiple racial and ethnic groups by including SEIR compartmental variables for each group, which interact through a social contact matrix that governs the interactions between and within groups. In matrix form, the structured SEIR model is given by:

$$
\frac{d \mathbf{S}}{d t}=-(\mathbf{B I}) \circ \mathbf{S}
$$

$$
\frac{d \mathbf{E}}{d t}=(\mathbf{B I}) \circ \mathbf{S}-r \mathbf{E}
$$

$$
\frac{d \mathbf{I}}{d t}=r \mathbf{E}-\gamma \mathbf{I}
$$

$$
\frac{d \mathbf{R}}{d t}=\gamma \mathbf{I}
$$

where $\circ$ denotes element-wise multiplication and $\mathbf{S}, \mathbf{E}, \mathbf{I}, \mathbf{R}$ are column vectors comprising the compartmental variables for each group (e.g., $\mathbf{S}=\left[S_{0}, \ldots, S_{p}\right]^{T}$ for $p$ demographic groups). We let $S_{0}$ denote non-Hispanic whites, $S_{1}$ denote Hispanics or Latinos, $S_{2}$ denote non-Hispanic African-Americans, $S_{3}$ denote non-Hispanic Asians, and $S_{4}$ denote multiracial or other demographic groups, with similar ordering for elements in vectors $\mathbf{E}$ through $\mathbf{R}$.

We define contacts to be interactions between individuals that allow for transmission of SARS-CoV2 with some non-zero probability. Following the convention for age-structured transmission models [31], we defined the $p \times p$ per capita social contact matrix $\mathbf{C}$ to consist of elements $c_{i \leftarrow j}$ at row $i$ and column $j$, representing the per capita rate that individuals from group $i$ are contacted by individuals of group $j$. Letting $N_{i}$ be the total number of individuals in group $i$, the social contact matrix $\mathbf{M}$ consists of elements $m_{i \leftarrow j}=c_{i \leftarrow j} * N_{i}$, which represents the average number of individuals in group $i$ encountered by an individual in group $j$. The susceptibility to infection can vary between groups, which we modeled by allowing the probability of infection given contact with an infected individual to vary: $\mathbf{q}=\left[q_{0}, \ldots, q_{p}\right]^{T}$. The transmission matrix $\mathbf{B}$ is then given by $\left(\mathbf{q} 1^{T}\right) \circ \mathbf{C}$, where $1^{T}$ is a 1 by $p$ vector of $1 \mathrm{~s}$ : 


$$
\mathbf{B}=\left[\begin{array}{ccccc}
q_{0} & \ldots & q_{0} & \ldots & q_{0} \\
\vdots & & \vdots & & \vdots \\
q_{4} & \ldots & q_{4} & \ldots & q_{4}
\end{array}\right] \circ\left[\begin{array}{ccccc}
c_{0 \leftarrow 0} & \ldots & c_{0 \leftarrow 2} & \ldots & c_{0 \leftarrow 4} \\
\vdots & & \vdots & & \vdots \\
c_{4 \leftarrow 0} & \ldots & c_{4 \leftarrow 2} & \ldots & c_{4 \leftarrow 4}
\end{array}\right]
$$

Given mean duration of infectiousness $1 / \gamma$, the next-generation matrix $\mathbf{G}$, representing the average number of infections in group $i$ caused by an infected individual in group $j$, is given by $\left(q 1^{T}\right) \circ \mathbf{M} / \gamma=$ $\mathbf{N} \circ \mathbf{B} / \gamma . R_{0}$ for the overall population described by this structured model was calculated by computing the dominant eigenvalue of matrix $\mathbf{G}$. The effective reproduction number $R_{t}$ at time $t$ was calculated by computing the dominant eigenvalue of $\mathbf{G}_{\mathbf{t}}=\left(\mathbf{q} 1^{T}\right) \circ \mathbf{M}_{\mathbf{t}} / \gamma=\mathbf{S}_{\mathbf{t}} \circ \mathbf{B} / \gamma$, where the elements in $\mathbf{M}_{\mathbf{t}}$ are given by $c_{i \leftarrow j} * S_{i, t}$ and $S_{i, t}$ is the number of susceptible individuals in group $i$ at time $t$. To hold $R_{0}$ values across model types constant when calculating HITs and final epidemic sizes, we rescaled transmission matrices to have the same dominant eigenvalue. We also calculated the instantaneous incidence rate of infection at some time $t$ for all groups by calculating the force of infection $\lambda_{\mathbf{t}}=\left(\mathbf{B I}_{\mathbf{t}}\right) \circ \mathbf{S}_{\mathbf{t}}$. To account for the effects of social distancing and other non-pharmaceutical interventions, we scaled the transmission rate by a factor $\alpha$ beginning when $5 \%$ cumulative incidence in the population was reached, representing an established and expanding epidemic, for a variable duration. We analyzed a range of $\alpha$ values to reflect the variation in NPIs implemented.

\section{Structured model variants}

Simplifying assumptions are needed to constrain the number of variables to estimate in $\mathbf{B}$ given limited data. Under the variable susceptibility model, we set the contact rates $c_{i \leftarrow j}$ to all be 1 , indicating no heterogeneity in exposure, but allowed the $q_{j}$ in the susceptibility vector to vary (i.e., $\left.\mathbf{B}=\mathbf{q} 1^{T}\right)$.

Under each of two variable exposure models, in contrast, we set the susceptibility factors $q_{j}$ to be equal. The simplest variable exposure model we analyzed was the proportionate mixing model, which assumes that the contact rate for each pair of groups is proportional to the total contact rate of the two groups (i.e., total number of contacts per unit time for an individual of group $i$ ) [32]. Denoting $a_{i}$ as the total contact rate for a member of group $i$ and a as the $1 \times p$ vector of $a_{i} \mathbf{s}$, the $i j$ th entry in the transmission matrix is given by:

$$
\beta_{i \leftarrow j}=q \frac{a_{i} a_{j}}{\sum_{k} a_{k} N_{k}}
$$


and the overall transmission matrix $\mathbf{B}$ can be written as:

$$
\mathbf{B}=\frac{q}{\sum_{k} a_{k} N_{k}} \mathbf{a a}^{T}
$$

Finally, under the assortative mixing assumption, we extended this model by partitioning a fraction $\epsilon$ of contacts to be exclusively within-group and distributed the rest of the contacts according to proportionate mixing (with $\delta_{i j}$ being an indicator variable that is 1 when $i=j$ and 0 otherwise) [32]:

$$
\beta_{i \leftarrow j}=(1-\epsilon) q \frac{a_{i} a_{j}}{\sum_{k} a_{k} N_{k}}+\epsilon \delta_{i j} q \frac{a_{i}}{N_{i}}
$$

$$
\mathbf{B}=\frac{(1-\epsilon) q}{\sum_{k} a_{k} N_{k}} \mathbf{a a}^{T}+\epsilon q \operatorname{diag}(\mathbf{a} \circ 1 / \mathbf{N})
$$

\section{Calculating the HIT and final epidemic size}

We defined the herd immunity threshold (HIT) for all models as the fraction of non-susceptible people when the effective reproduction number $R_{t}$ first crosses 1 . In the homogenous model, where $R_{t}=S_{t} \beta / \gamma$, the analytical solution for the HIT occurs when the fraction of non-susceptible individuals equals $1-1 / R_{0}$. In the structured models of heterogeneous populations, the HIT was calculated via simulation: we took the dominant eigenvalue of $\mathbf{G}_{\mathbf{t}}$ at each timestep to calculate $R_{t}$, and identified the number of non-susceptible individuals when $R_{t}$ first decreased below 1 . For the heterogeneous models with mitigation measures, $R_{t}$ was calculated at each timestep with respect to the corresponding unmitigated epidemic; in other words, the mitigation scaling factor $\alpha$ was not included in the $R_{t}$ calculation. This identifies the point in the epidemic trajectory at which the population reaches the HIT even if all mitigation measures were lifted (i.e. HIT due to population immunity), as opposed to the point in the trajectory when the population transiently reaches the HIT due to mitigation measures (see Supplementary Figure 17 for further explanation).

Final epidemic sizes were calculated by simulation by running the epidemic out to 1 year for $R_{0}$ above 2, and 4 years for $R_{0}$ below 2 to allow additional time for the slower epidemics to fully resolve. The final time point was used as the estimate for the final epidemic size.

\section{Model fitting and data sources}

SEIR differential equations were solved using the Isoda function in the deSolve package (version 1.28) of $\mathrm{R}$ (version 3.6.3). We estimated the $a_{i}$ in the variable exposure models and the $q_{i}$ in the 
medRxiv preprint doi: https://doi.org/10.1101/2021.01.15.21249881; this version posted May 1, 2021. The copyright holder for this preprint (which was not certified by peer review) is the author/funder, who has granted medRxiv a license to display the preprint in perpetuity. It is made available under a CC-BY-NC-ND 4.0 International license .

variable susceptibility models using maximum likelihood fits to a single cross-sectional serosurvey from New York, which was collected from over 15,000 adults in grocery stores from April 19-28th [16]. We assumed that the seroprevalence data (adjusted cumulative incidence estimates from Table 2 in Rosenberg et al., 2020) were collected via a binomial sampling process: at a given time point $t_{s}$ representing the time of the serosurvey, the number of seropositive cases $Y_{i}\left(t_{s}\right)$ in group $i$ is distributed $\operatorname{Bin}\left(m_{i}, R_{i}\left(t_{s}\right) / N_{i}\left(t_{s}\right)\right)$, where $m_{i}$ is the number of people tested from group $i$ in the serosurvey and $R_{i} / N_{i}$ is the fraction of recovered people from the SEIR model. The likelihood was calculated jointly for all demographic groups, with $t_{s}$ set to 100 days and the initial number of infected individuals set to 1 in each demographic group; see Supplementary Information for sensitivity analyses on these assumptions.

We acquired total population numbers (i.e. $N_{i}$ for $i \in\{0, \ldots, 4\}$ ) from the 2018 ACS census 1-year estimates Table B03002 (Hispanic or Latino origin by race) subsetted to the following counties: Bronx, Kings, New York, Queens, and Richmond Counties for New York City and Nassau and Suffolk Counties for Long Island. We acquired population numbers at the level of "all block groups" within the above counties from the 2018 ACS 5-year estimates Table B03002 (Hispanic or Latino origin by race). Copies of the census data we used are available at https://github.com/kevincma/ covid19-race-ethnicity-model/tree/main/data.

The total number of contacts $C_{i j}$ between groups $i$ and $j$ can be calculated using the assortative mixing social contact matrix.

$$
C_{i j}=c_{i j} N_{i} N_{j}=(1-\epsilon) \frac{a_{i} a_{j} N_{i} N_{j}}{\sum_{k} a_{k} N_{k}}+\epsilon \delta_{i j} a_{i} N_{j}
$$

To fit this assortative mixing model to both serosurvey and census data, we modeled interactions between racial and ethnic groups at the census block group level - which we interpreted to be roughly equivalent to neighborhoods - allowing the structure of the census data to inform the dynamics of transmission. Specifically, we assumed proportionate mixing between racial and ethnic groups in each census block group, with no interactions between block groups. Under this proportionate mixing within neighborhoods assumption, the total number of contacts $C_{i j}^{\prime}$ between groups $i$ and $j$ is proportional to: 


$$
C_{i j}^{\prime} \propto \sum_{l}^{L} a_{i} a_{j} N_{i, l} N_{j, l}
$$

where $L$ is the number of census block groups, $N_{j, l}$ is the number of people from demographic group $j$ in census block $l$, and $a_{j}$ is the total contact rate per individual in group $j$ as before. Within each neighborhood, proportionate mixing holds: the total number of contacts between two groups is proportional to the activity level and neighborhood population of the groups. Additionally, similarly to the previous models, the total number of contacts across all groups $\left(\sum_{i j} C_{i j}^{\prime}\right)$ must equal $\sum_{k} a_{k} N_{k}$; to satisfy this constraint, we set a proportionality constant:

$$
C_{i j}^{\prime}=\frac{\sum_{k} a_{k} N_{k}}{\sum_{i j l} a_{i} a_{j} N_{i, l} N_{j, l}} \sum_{l}^{L} a_{i} a_{j} N_{i, l} N_{j, l}
$$

To fit $\epsilon$, we minimized the absolute difference between these two formulations $\left(C_{i j}\right.$ and $\left.C_{i j}^{\prime}\right)$ of the total number of contacts across all pairs of groups (Supplementary Figure 7):

$$
\begin{gathered}
\hat{\epsilon}=\underset{\epsilon}{\operatorname{argmin}} \sum_{i j}\left|C_{i j}-C_{i j}^{\prime}\right|= \\
\underset{\epsilon}{\operatorname{argmin}} \sum_{i j}\left|(1-\epsilon) \frac{a_{i} a_{j} N_{i} N_{j}}{\sum_{k} a_{k} N_{k}}+\epsilon \delta_{i j} a_{i} N_{j}-\frac{\sum_{k} a_{k} N_{k}}{\sum_{i j l} a_{i} a_{j} N_{i, l} N_{j, l}} \sum_{l}^{L} a_{i} a_{j} N_{i, l} N_{j, l}\right|
\end{gathered}
$$

Using the fitted value $\hat{\epsilon}$, we then conducted maximum-likelihood to fit the varying $a_{i}$ as described previously. We repeated this process iteratively - holding $a_{i}$ constant while $\epsilon$ was fit, and then viceversa - until convergence, which we defined as the difference between successive $\hat{\epsilon}$ values being lower than a threshold of 0.001 (Supplementary Tables 4 and 5). For the first iteration, we fit $\hat{\epsilon}$ holding $a_{i}$ constant at 1 . We used this iterative fitting procedure to accommodate both the seroprevalence and census data because the single seroprevalence time point cannot fit both the activity levels and $\epsilon$.

To empirically characterize average neighborhood composition from the census data, we also calculated the exposure index matrix $P$ with elements $P_{i j}$ for demographic groups $i$ and $j$, defined similarly to [33, 34]: 


$$
P_{i j}=\sum_{l}^{L}\left(\frac{N_{j, l}}{N_{j}}\right)\left(\frac{N_{i, l}}{T_{l}}\right)
$$

where $T_{l}$ is the total number of people in census block group $l$ and other variables are defined as before. The exposure indices were used for descriptive purposes only and not used in the model fitting approach.

\section{Code availability}

Code and data to reproduce all analyses and figures is available at https://github.com/kevincma/ covid19-race-ethnicity-model. An executable version of the Jupyter notebook is available at https://mybinder.org/v2/gh/kevincma/covid19-race-ethnicity-model/HEAD

\section{Results}

We model the dynamics of COVID-19 infection allowing for social exposure to infection to vary across racial and ethnic groups. Models incorporating variable susceptibility to COVID-19 are commonly used when stratifying by age because children are thought to have decreased susceptibility to infection [10]. Variable susceptibility to infection across racial and ethnic groups has been less well characterized, and observed disparities in infection rates can already be largely explained by differences in mobility and exposure [25-27], likely attributable to social factors such as structural racism that have put racial and ethnic minorities in disadvantaged positions (e.g., employment as frontline workers and residence in overcrowded, multigenerational homes) [35-38]. In line with the notion that variation in exposure could instead be the main driver of observed seroprevalence differences, our primary focus is on analyzing variable exposure models; we have also analyzed variable susceptibility models for comparison (see Supplementary Information).

The simplest variable exposure models assume proportionate mixing, where the contact rate between groups is set to be proportional to the total contact rates (i.e., total number of contacts per time period per individual) of the two groups [32]. We fit proportionate mixing models allowing for variable contact rates across racial and ethnic demographic groups to serosurvey data collected in late-April from New York City (NYC) and Long Island, comprising 5946 and 2074 adults, respectively [16]. The serosurvey data were compatible with proportionate mixing models in which Hispanics or Latinos, non-Hispanic Black people, non-Hispanic Asians, and multiracial or other people had 2.25, 1.62, 0.86, and 1.28 times the total contact rates relative to non-Hispanic whites in 
medRxiv preprint doi: https://doi.org/10.1101/2021.01.15.21249881; this version posted May 1, 2021. The copyright holder for this preprint (which was not certified by peer review) is the author/funder, who has granted medRxiv a license to display the preprint in perpetuity.
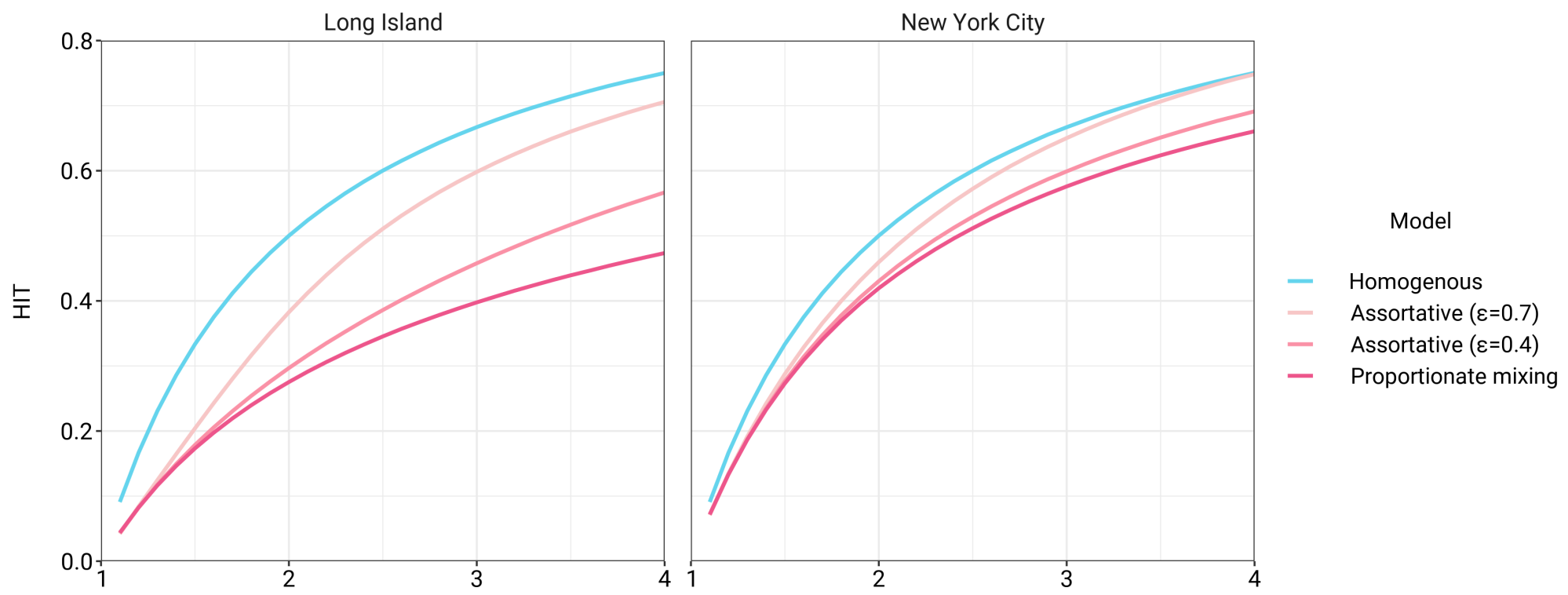

RO

Figure 1: Incorporating assortativity in variable exposure models results in increased HITs across a range of $R_{0}$ values. Variable exposure models were fitted to NYC and Long Island serosurvey data.

NYC. Model fits to Long Island resulted in even more pronounced exposure differences because of greater between-group differences in seropositivity (e.g., the seropositivity in Hispanics or Latinos relative to non-Hispanic whites was 1.85 times higher in Long Island than in NYC). Under proportionate mixing, Hispanics or Latinos, non-Hispanic Black people, non-Hispanic Asians, and multiracial or other people had $4.31,1.96,0.92$, and 2.48 times the fitted total contact rates relative to non-Hispanic whites in Long Island, respectively. These differences in exposure impacted herd immunity levels and final epidemic sizes relative to the homogeneous model across a range of $R_{0}$ values (Figure 1 and Supplementary Figure 5); for example, for an $R_{0}$ of 3 , the HIT decreases to $58 \%$ in NYC and $40 \%$ in Long Island, compared to $67 \%$ under the homogeneous model. The observed contrast in HITs and final sizes between the proportionate mixing and the homogenous model is in line with theoretical derivations (Supplementary Figure 4). The HIT overall is reached in this model after cumulative incidence has disproportionately increased in certain minority groups: at the HIT, $75 \%$ of Hispanics or Latinos and $63 \%$ of non-Hispanic Black people were infected compared to $46 \%$ of non-Hispanic whites in NYC, and $77 \%$ of Hispanics or Latinos and $48 \%$ of non-Hispanic Black people were infected compared to $29 \%$ of non-Hispanic whites in Long Island (Figure 2).

The estimated total contact rate ratios indicate increased contacts for minority groups such as His- 
medRxiv preprint doi: https://doi.org/10.1101/2021.01.15.21249881; this version posted May 1, 2021. The copyright holder for this preprint (which was not certified by peer review) is the author/funder, who has granted medRxiv a license to display the preprint in perpetuity. It is made available under a CC-BY-NC-ND 4.0 International license .

panics or Latinos and non-Hispanic Black people, which is in line with studies using cell phone mobility data [25]; however, the magnitudes of the ratios are substantially higher than one would expect given the findings from those studies. This may reflect some of the limitations of the proportionate mixing assumption, which does not allow for preferential within-group contacts and hence must fit observed seropositivity differences solely by scaling total contact rates. To address this, we augment the model by partitioning a specified fraction $\epsilon$ of contacts to be exclusively within-group, with the remaining contacts distributed proportionately. This assortative mixing model captures more realistic patterns of interactions due to neighborhood structure. After fitting the models across a range of $\epsilon$ values, we observed that as $\epsilon$ increases, HITs and epidemic final sizes shifted higher back towards the homogeneous case (Figure 11, Supplementary Figure 5); this effect was less pronounced for $R_{0}$ values close to 1 . This observation can be understood by comparing the epidemic cumulative incidence trajectories (Supplementary Figure 6) and next-generation matrices (Supplementary Figures 2 and 3$)$ : under proportionate mixing $(\epsilon=0)$, lower-risk demographic groups are protected from further infection due to built-up immunity in higher-risk demographic groups, but the magnitude of this indirect protection decreases as the proportion of exclusively within-group contacts increases and groups become more isolated.

We assessed a range of values for $\epsilon$ because the serosurvey data cannot be used to also fit the optimal $\epsilon$ value; given limited numbers of data points, any value of $\epsilon$ can fit exactly to the single seroprevalence time point we consider. To inform plausible assortativity levels, we instead used additional data on demographic population distributions from the American Community Survey US census stratified at the census block group level, which represents a small geographic area and population (Supplementary Figure 17). We first calculated the exposure index, which represents the average neighborhood's demographic composition from the perspective of an individual from a given racial or ethnic group; the proportion of contacts within group were elevated, suggesting assortativity in the census data (Supplementary Tables 1 and 2). To directly fit $\epsilon$ with these data, we assumed proportionate mixing within census block groups and ran an iterative fitting approach to jointly fit $\epsilon$ and the $a_{i}$ total contact rates using both census and serosurvey data (see methods and Supplementary Tables 4 and 5). This approach accounts for contacts based on geographic proximity using strong assumptions on mixing patterns, but may not capture contacts in other settings, such as work, beyond one's immediate neighborhood of residence. The models jointly fitted to serosurvey and census data indicated that $46 \%$ and $39 \%$ of contacts were exclusively within-group in NYC and Long Island, respectively. The same groups had elevated total contact rates as under proportionate 
medRxiv preprint doi: https://doi.org/10.1101/2021.01.15.21249881; this version posted May 1, 2021. The copyright holder for this preprint (which was not certified by peer review) is the author/funder, who has granted medRxiv a license to display the preprint in perpetuity. It is made available under a CC-BY-NC-ND 4.0 International license .

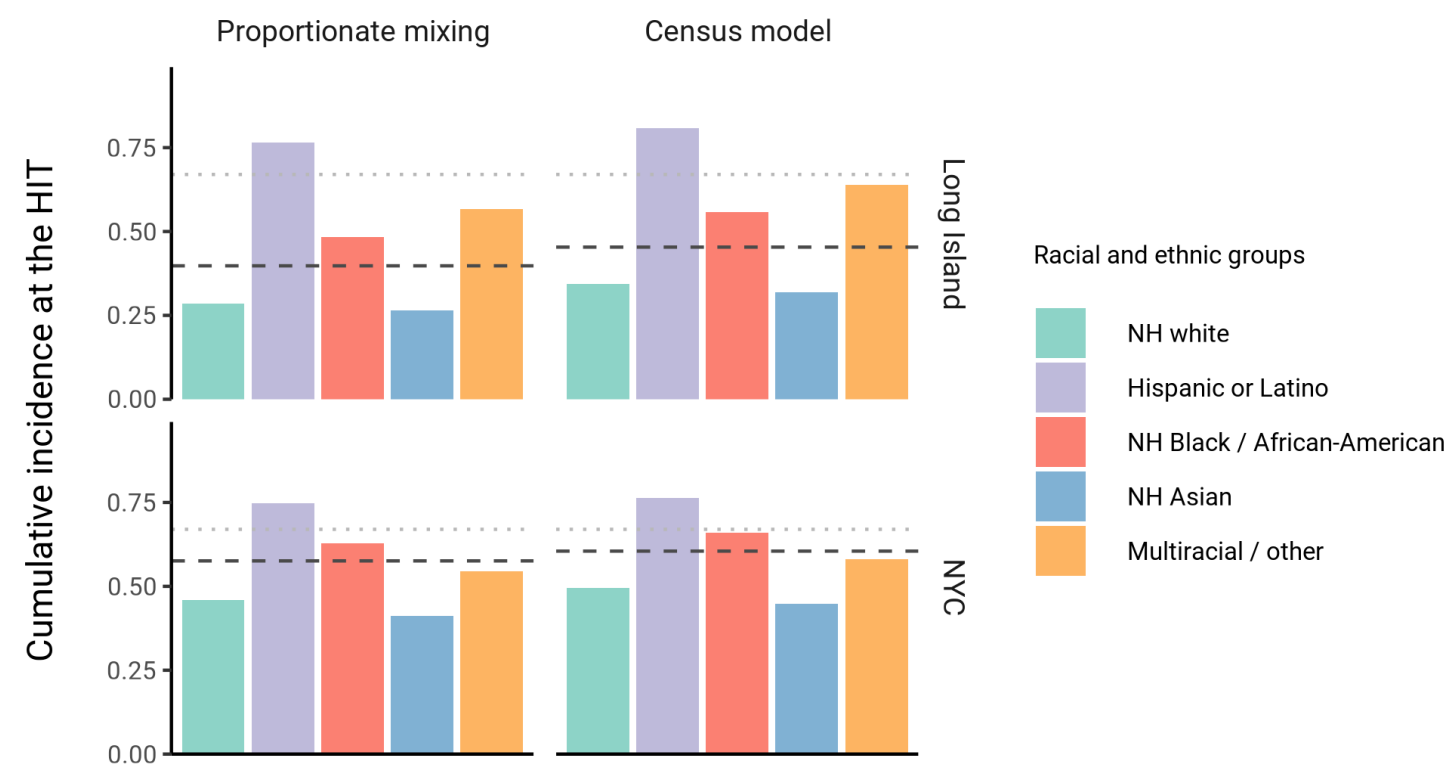

Figure 2: Cumulative incidence is disproportionately higher in some racial and ethnic minorities when the overall HIT is reached across model types and locations. Results are shown for an epidemic with $R_{0}=3$. The HIT for the population is indicated with a black line, and the HIT for a homogeneous model with the same $R_{0}$ is indicated with a gray line.

mixing, but the magnitudes of differences were now lower and more concordant with reported mobility differences [25]: model estimates indicated Hispanics or Latinos, non-Hispanic Black people, non-Hispanic Asians, and multiracial or other people had 1.62, 1.35, 0.90, and 1.17 times the total contact rate relative to non-Hispanic whites in NYC, respectively, and 2.60, 1.63, 0.93, and 1.90 times the total contact rate relative to non-Hispanic whites in Long Island, respectively. For an epidemic with $R_{0}=3$, the HITs for NYC and Long Island using these census-informed assortativity models were $61 \%$ and $45 \%$, respectively. Similar to previous models, at the HIT, $76 \%$ of Hispanics or Latinos and $66 \%$ of non-Hispanic Black people were infected compared to $50 \%$ of non-Hispanic whites in NYC, and $81 \%$ of Hispanics or Latinos and $56 \%$ of non-Hispanic Black people were infected compared to $34 \%$ of non-Hispanic whites in Long Island (Figure 2).

Using these census-informed assortative mixing models, we then considered how the relative incidence rates of infection in demographic groups could change over the course of the epidemic. Early comparisons of infection and mortality rates have helped to identify racial and ethnic groups at high risk and the risk factors for infection [18-24], but these studies often rely on cross-sectional snapshots of epidemiological patterns. The challenge is that these metrics can change over time: for 

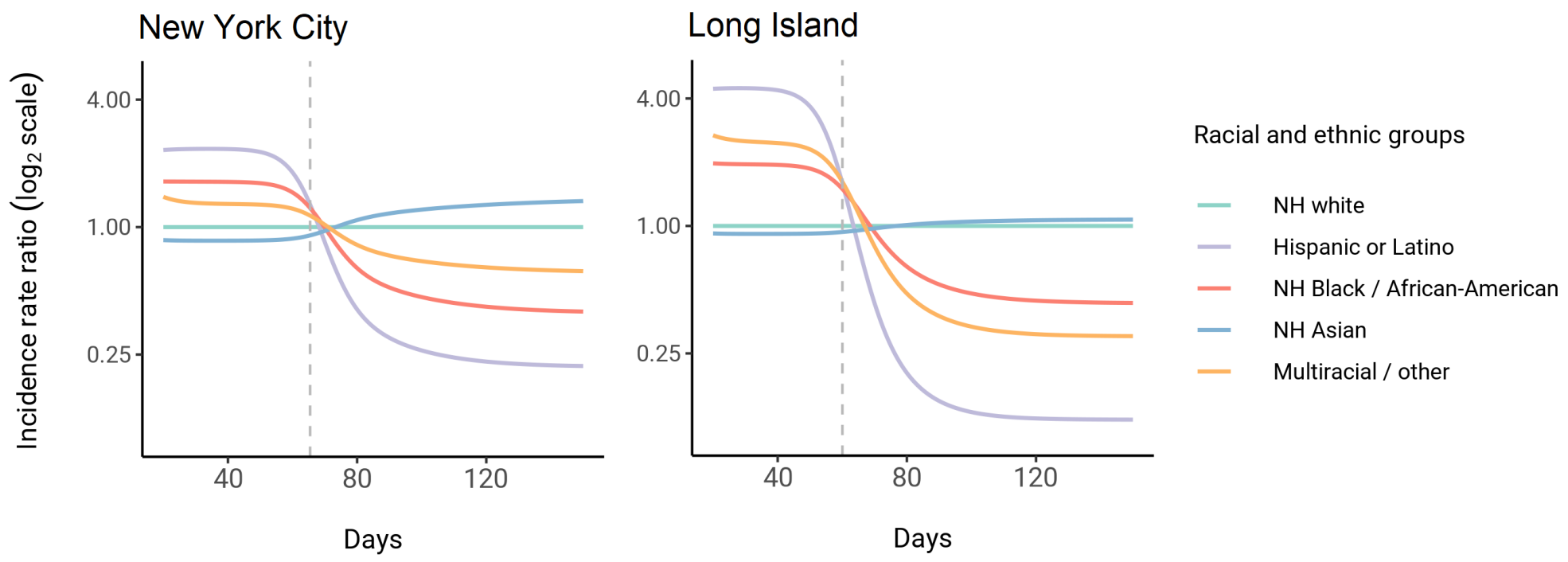

Figure 3: Dynamics of incidence rate ratios relative to non-Hispanic whites in assortative mixing models fitted to census and serosurvey data. Dashed line represents the peak overall incidence for the epidemic.

instance, multiple studies indicate decreasing disparities in incidence rate over time across racial and ethnic groups relative to non-Hispanic whites [39, 40]. The reasons for these changes are multifaceted, but even independent of the effect of interventions, behavioral changes, or differential access to testing, models of epidemic spread in structured populations imply that incidence rate ratios for high-risk groups can decrease substantially as the epidemic progresses because of depletion of susceptible individuals from these groups [41, 42]. In line with this, we observe that instantaneous incidence rate ratios are elevated initially in high-contact groups relative to non-Hispanic whites, but this trend reverses after the epidemic has peaked and overall incidence is decreasing - a consequence of the fact that a majority of individuals have already become infected (Figure 3). Similarly, cumulative incidence ratios remain elevated in high-contact racial and ethnic groups throughout the epidemic, but the magnitude decreases as the epidemic progresses (Supplementary Figure 8). Although these trajectories are not meant to be taken as predictive estimates, these results highlight the importance of controlling for dynamics-induced changes in epidemiological measures of disease burden when evaluating the impact of interventions for reducing inequities in SARS-CoV-2 infections [43]; otherwise, ineffective interventions - depending on their timing - might still be associated with declines in relative measures of disease burden.

Finally, we assessed how robust these findings were to the impact of social distancing and other 
medRxiv preprint doi: https://doi.org/10.1101/2021.01.15.21249881; this version posted May 1, 2021. The copyright holder for this preprint (which was not certified by peer review) is the author/funder, who has granted medRxiv a license to display the preprint in perpetuity. It is made available under a CC-BY-NC-ND 4.0 International license .

non-pharmaceutical interventions (NPIs). We modeled these mitigation measures by scaling the transmission rate by a factor $\alpha$ beginning when $5 \%$ cumulative incidence in the population was reached. Setting the duration of distancing to be 50 days and allowing $\alpha$ to be either 0.3 or 0.6 (i.e. a $70 \%$ or $40 \%$ reduction in transmission rates, respectively), we assessed how the $R_{0}$ versus HIT and final epidemic size relationships changed. We found that the $R_{0}$ versus HIT relationship was similar to in the unmitigated epidemic (Supplementary Figure 9). In contrast, final epidemic sizes depended on the intensity of mitigation measures, though qualitative trends across models (e.g. increased assortativity leads to greater final sizes) remained true (Supplementary Figure 10). To explore this further, we systematically varied $\alpha$ and the duration of NPIs while holding $R_{0}$ constant at 3 . We found again that the HIT was consistent, whereas final epidemic sizes were substantially affected by the choice of mitigation parameters (Supplementary Figure 11); the distribution of cumulative incidence at the point of HIT was also comparable with and without mitigation measures (Supplementary Figure 12). The most stringent NPI intensities did not necessarily lead to the smallest epidemic final sizes, an idea which has been explored in studies analyzing optimal control measures [44, 45]. Longitudinal changes in incidence rate ratios also were affected by NPIs, but qualitative trends in the ordering of racial and ethnic groups over time remained consistent (Supplementary Figure 13).

\section{Discussion}

Here, we explored how incorporating heterogeneity in SARS-CoV-2 spread across racial and ethnic groups could affect epidemic dynamics using deterministic transmission models. Models incorporating variable exposure generally decreased the HIT and final epidemic size, but incorporating preferential within-group contacts shifted HITs and final epidemic sizes higher, approaching the homogeneous case. Epidemiological measures of disease burden such as incidence rate ratios and cumulative incidence ratios also changed substantially over the course of the epidemic, highlighting the need to account for these trends when evaluating interventions [43]. These results illustrate the varied effects of different structured heterogeneity models, but are not meant to be best estimates given the limited seroprevalence data.

Across all model variants, the observed higher cumulative incidence among Hispanics or Latinos and non-Hispanic Black people compared to non-Hispanic whites led to estimates of higher estimated contacts relative to non-Hispanic whites, mirroring existing inequities in housing, education, healthcare, and beyond [20, 38, 46-48]. The estimated contact rate differences also concord with 
medRxiv preprint doi: https://doi.org/10.1101/2021.01.15.21249881; this version posted May 1, 2021. The copyright holder for this preprint (which was not certified by peer review) is the author/funder, who has granted medRxiv a license to display the preprint in perpetuity. It is made available under a CC-BY-NC-ND 4.0 International license .

reports that frontline workers, who are unable to engage in physical or social distancing to the same degree as other types of workers, are disproportionately from minority backgrounds [25, 27, 49]. The assortativity we observed in the census data has root causes in many areas, including residential segregation arising from a long history of discriminatory practices [46, 48, 50, 51]. Projecting the epidemic forward indicated that the overall HIT was reached after cumulative incidence had increased disproportionately in minority groups, highlighting the fundamentally inequitable outcome of achieving herd immunity through infection. All of these factors underscore the fact that incorporating heterogeneity in models in a mechanism-free manner can conceal the disparities that underlie changes in epidemic final sizes and HITs. In particular, overall lower HIT and final sizes occur because certain groups suffer not only more infection than average, but more infection than under a homogeneous mixing model; incorporating heterogeneity lowers the HIT but increases it for the highest-risk groups (Figure 2).

These results also suggest that public health interventions for reducing COVID-19 inequities can have synergistic effects for controlling the overall epidemic [34]. For instance, from a transmissioncontrol perspective, age-structured models indicate that vaccination of high-contact age groups such as young adults - is optimal for controlling the spread of SARS-CoV-2 [9]. Similar interventions are being explored for disadvantaged populations because of how increased exposure underlies much of the higher infection risk that racial and ethnic minorities experience. For instance, Mulberry et al. used a structured SEIR model to evaluate the impact of preferentially vaccinating essential workers, finding that such a strategy was more effective in reducing morbidity, mortality, and economic cost due to COVID-19 compared to age-only vaccination prioritization strategies [52]. Because racial and ethnic minorities are overrepresented among essential workers [25, 27, 49], further modeling studies could evaluate the impact of such strategies on also reducing inequities in COVID-19 infection rates. Wrigley-Field et al. took a different methodological approach, projecting demographically-stratified death rates from 2020 into 2021 assuming various vaccination strategies [53]. In line with the prior study, they found that vaccination strategies that prioritized geographic areas based on socioeconomic criteria or prior COVID mortality rates outperformed age-based strategies in reducing overall mortality and inequities in mortality. Because populations here were considered independently, these results could be extended using a transmission modeling framework, such as the one we have described, that accounts for interactions between racial and ethnic groups and thus allows for synergistic benefits from vaccinating high-risk populations. All policy proposals in this space should, of course, carefully consider the legal and ethical dimensions of vaccinations 
medRxiv preprint doi: https://doi.org/10.1101/2021.01.15.21249881; this version posted May 1, 2021. The copyright holder for this preprint (which was not certified by peer review) is the author/funder, who has granted medRxiv a license to display the preprint in perpetuity. It is made available under a CC-BY-NC-ND 4.0 International license .

or other interventions targeted by race or ethnicity [54].

We note several limitations with this study. First, biases in the serosurvey sampling process can substantially affect downstream results; any conclusions drawn depend heavily on the degree to which serosurvey design and post-survey adjustments yield representative samples [55]. For instance, because the serosurvey we relied on primarily sampled people at grocery stores, there is both survival bias (cumulative incidence estimates do not account for people who have died) and ascertainment bias (undersampling of at-risk populations that are more likely to self-isolate, such as the elderly) [16, 56]. These biases could affect model estimates if, for instance, the capacity to self-isolate varies by race or ethnicity - as suggested by associations of neighborhood-level mobility versus demographics [27, 57] - leading to an overestimate of cumulative incidence and contact rates in whites. Other sources of uncertainty, such as antibody test sensitivity and specificity, could also be incorporated into transmission models in future work [56, 58]. Second, we have assumed that seropositivity implies complete immunity and that immunity does not wane. These are strong assumptions that can be revisited as empirical studies on the length of natural immunity are conducted. Third, we have assumed the impact of non-pharmaceutical interventions such as stay-athome policies, closures, and the like to equally affect racial and ethnic groups. Empirical evidence suggests that during periods of lockdown, certain neighborhoods that are disproportionately wealthy and white tend to show greater declines in mobility than others [27, 57]. These simplifying assumptions were made to aid in illustrating the key findings of this model, but for more detailed predictive models, the extent to which contact rate differences change could be evaluated using longitudinal contact survey data [59], since granular mobility data are typically not stratified by race and ethnicity due to privacy concerns [60]. Fourth, due to data availability, we have only considered variability in exposure due to one demographic characteristic; models should ideally strive to also account for the effects of age on susceptibility and exposure within strata of race and ethnicity and other relevant demographics, such as socioeconomic status and occupation [52]. These models could be fit using representative serological studies with detailed cross-tabulated seropositivity estimates. Finally, we have estimated model parameters using a single cross-sectional serosurvey. To improve estimates and the ability to distinguish between model structures, future studies should use longitudinal serosurveys or case data stratified by race and ethnicity and corrected for underreporting; the challenge will be ensuring that such data are systematically collected and made publicly available, which has been a persistent barrier to research efforts [28]. Addressing these data barriers will also be key for translating these and similar models into actionable policy proposals on vaccine distribution and 
medRxiv preprint doi: https://doi.org/10.1101/2021.01.15.21249881; this version posted May 1, 2021. The copyright holder for this preprint (which was not certified by peer review) is the author/funder, who has granted medRxiv a license to display the preprint in perpetuity. It is made available under a CC-BY-NC-ND 4.0 International license.

non-pharmaceutical interventions.

In summary, we have explored how deterministic transmission models can be extended to study the dynamics of infection in racial and ethnic groups, and how the impact of heterogeneity on the HIT and final epidemic size depends strongly on the details of how heterogeneity is modeled. We have shown that due to early infections in individuals from the most at-risk groups, relative measures of incidence may decline and even reverse, but inequities in the cumulative burden of infection persist throughout the epidemic as the HIT is reached. These results describe a framework that can be extended to other cities and countries in which racial and ethnic disparities in seropositivity have been observed [17, 61, 62] and are a step towards using transmission models to design policy interventions for reducing disparities in COVID-19 and other diseases. 
medRxiv preprint doi: https://doi.org/10.1101/2021.01.15.21249881; this version posted May 1, 2021. The copyright holder for this preprint (which was not certified by peer review) is the author/funder, who has granted medRxiv a license to display the preprint in perpetuity. It is made available under a CC-BY-NC-ND 4.0 International license.

\section{Acknowledgements}

We thank Dr. Eli Rosenberg at the University at Albany School of Public Health and members of the Center for Communicable Disease Dynamics and Dr. Mary Bassett at the Harvard T.H. Chan School of Public Health for helpful comments. K.C.M. was supported by National Science Foundation GRFP grant DGE1745303. Y.H.G. and M.L. were funded by the Morris-Singer Foundation. 
medRxiv preprint doi: https://doi.org/10.1101/2021.01.15.21249881; this version posted May 1, 2021. The copyright holder for this preprint (which was not certified by peer review) is the author/funder, who has granted medRxiv a license to display the preprint in perpetuity. It is made available under a CC-BY-NC-ND 4.0 International license .

\section{Supplementary Information}

\section{Variable susceptibility versus variable exposure models}

The serosurvey data were compatible with variable susceptibility models in which Hispanics or Latinos, non-Hispanic Black people, non-Hispanic Asians, and multiracial or other people had 2.25, $1.62,0.86$, and 1.28 times the susceptibility to infection relative to non-Hispanic whites in NYC, respectively, and 4.32, 1.96, 0.92, and 2.48 times the susceptibility to infection relative to non-Hispanic whites in Long Island, respectively. As with variable exposure models, these differences in susceptibility lowered herd immunity levels and final epidemic sizes relative to the homogeneous model (Supplementary Figure 1), but to a lesser extent; for instance, variable susceptibility models resulted in HITs $\sim 10 \%$ greater than HITs under proportionate mixing for Long Island.

The difference between these models is that incorporating heterogeneity in susceptibility only affects susceptible individuals, but heterogeneity in exposure impacts both susceptible and infectious individuals: individuals from racial and ethnic groups with higher contact rates are both more likely to be infected, and when infected, to infect a greater number of secondary cases. This contrast is clear when comparing the next-generation matrices for each model, which lists the average number of secondary infections caused by an infected individual from a given demographic group (Supplementary Figures 2 and 3). The epidemic resolves at an earlier stage in variable exposure models once these key transmission groups become immune because of this additional compound effect on transmission.

Our results contrasting mechanistic variable exposure and susceptibility models are in line with theoretical studies, which also indicate that models incorporating heterogeneity in exposure have more pronounced effects on HITs than models incorporating heterogeneity in susceptibility, assuming comparable continuous distributions of exposure and susceptibility [4, 6]. Tkachenko et al. showed that the $H I T=1-\left(1 / R_{0}\right)^{(1 / \lambda)}$, where $\lambda$ is either $1+C V^{2}$ for variable susceptibility models or $1+C V^{2}\left(2+\gamma_{s} C V\right) /\left(1+C V^{2}\right)$ for variable exposure models, and $C V$ is the coefficient of variation and $\gamma_{s}$ is the skewness for the exposure distribution [6]. We calculated CV and skewness using the susceptibility and total contact rate ratios and substituted those values into the HIT formula, which is an approximation because our exposure and susceptibility distributions are discrete; nonetheless, the approximations result in similar HIT curves to the simulation results (Supplementary Figure 4). 
medRxiv preprint doi: https://doi.org/10.1101/2021.01.15.21249881; this version posted May 1, 2021. The copyright holder for this preprint (which was not certified by peer review) is the author/funder, who has granted medRxiv a license to display the preprint in perpetuity. It is made available under a CC-BY-NC-ND 4.0 International license.

\section{Sensitivity analyses}

We conducted sensitivity analyses to assess whether assumptions on epidemic timing, and number and distribution of initial infected individuals affected parameter and HIT estimates. Varying the timing of epidemic start did not substantially affect HIT estimates, as long as the time between epidemic start and serosurvey $t_{s}$ was reasonable large (e.g., $>20$ days) and assortativity was low $(\epsilon<0.8)$ (Supplementary Figure 14). The distribution and number of initial infected individuals also did not substantially affect HIT estimates for low levels of assortativity $(\epsilon<0.8)$ (Supplementary Figures 15 and 16). We limited our analyses to models with $\epsilon$ less than 0.8 . 
medRxiv preprint doi: https://doi.org/10.1101/2021.01.15.21249881; this version posted May 1, 2021. The copyright holder for this preprint (which was not certified by peer review) is the author/funder, who has granted medRxiv a license to display the preprint in perpetuity.

It is made available under a CC-BY-NC-ND 4.0 International license .
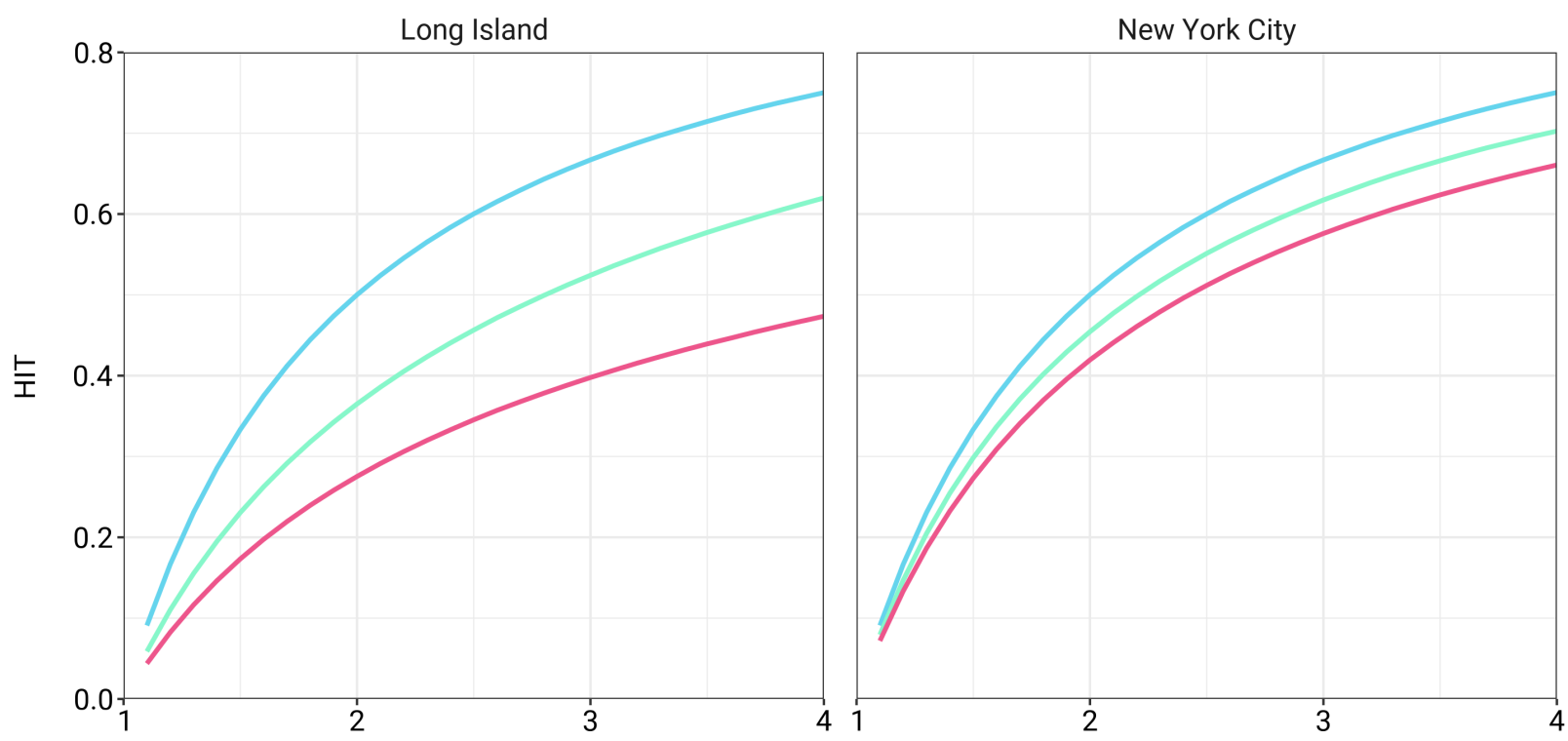

Model

- Homogenous

- Susceptibility

- Proportionate mixing

449

$\mathrm{RO}$
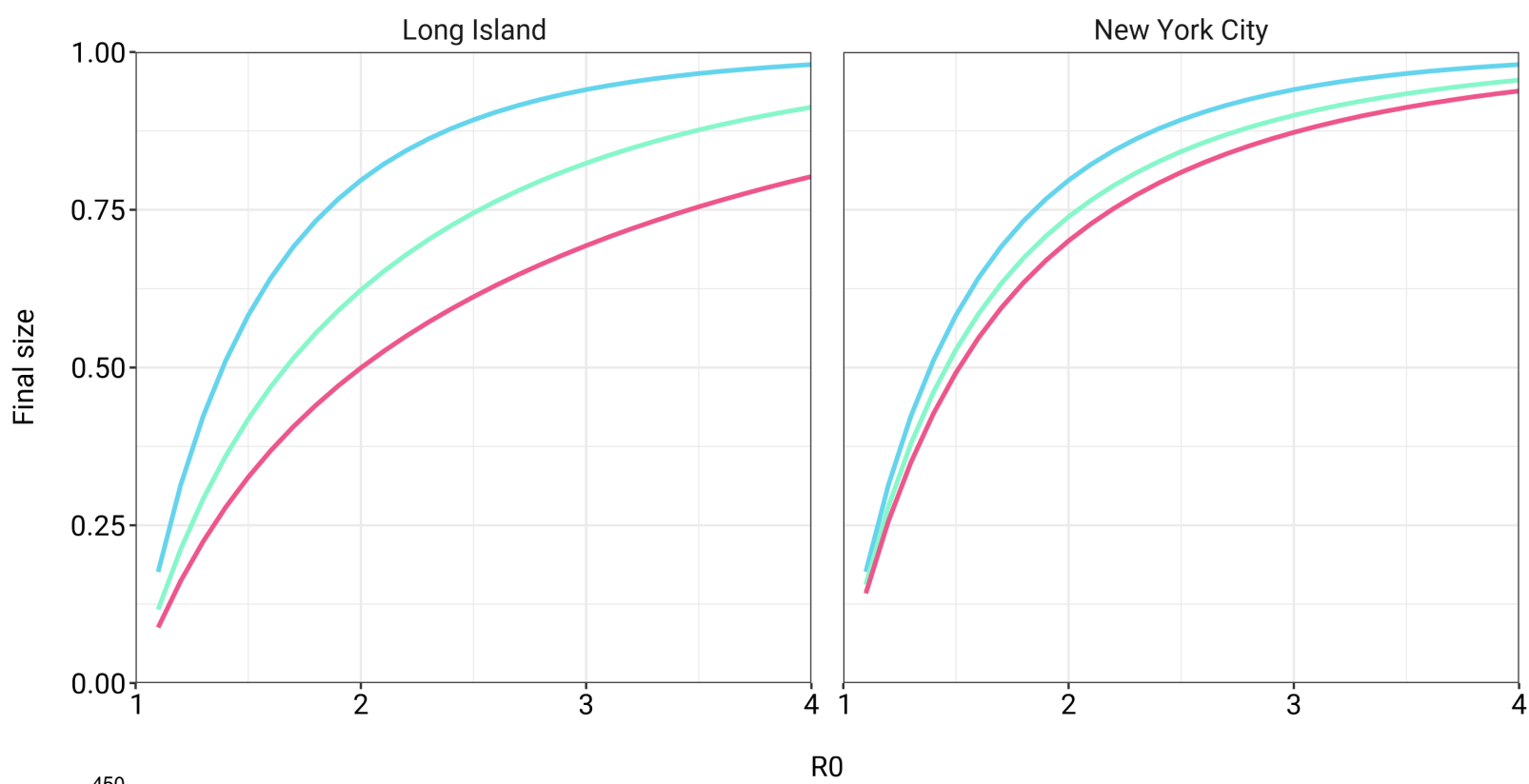

Model

- Homogenous

- Susceptibility

- Proportionate mixing

450

$\mathrm{RO}$

451

452

453

Supplementary Figure 1: Models incorporating variable susceptibility to COVID-19 fitted to NYC and Long Island serosurvey data result in reduced HITs (top) and final epidemic sizes (bottom) across a range of $R_{0}$ values. 
medRxiv preprint doi: https://doi.org/10.1101/2021.01.15.21249881; this version posted May 1, 2021. The copyright holder for this preprint (which was not certified by peer review) is the author/funder, who has granted medRxiv a license to display the preprint in perpetuity.

It is made available under a CC-BY-NC-ND 4.0 International license .

454

455

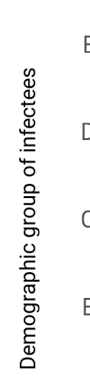

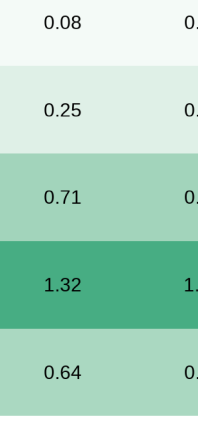

A

$0.08 \quad 0.08$

0.25

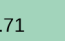

.

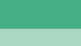

0.64

B

Demographic group of infector

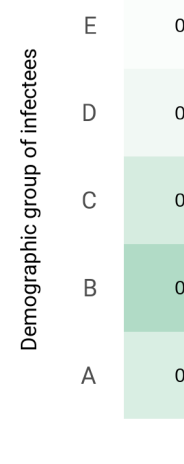

A

A

Demographic group of infector

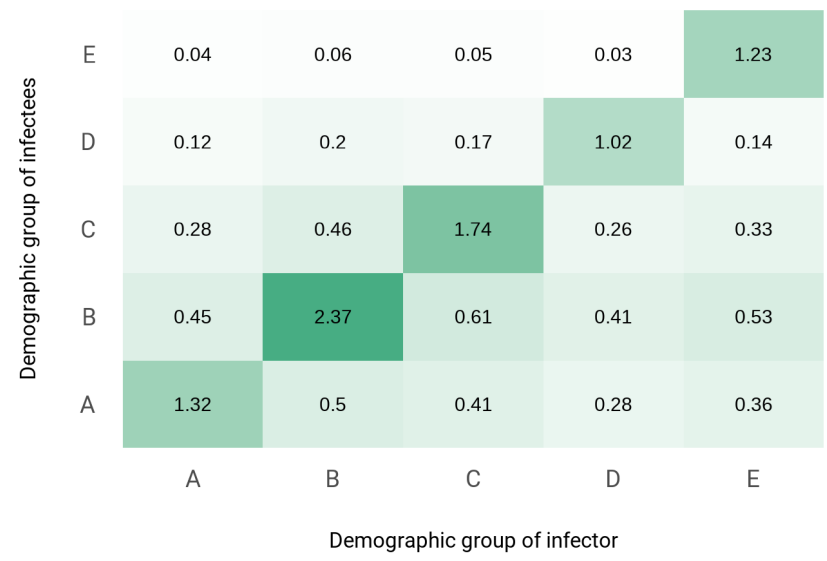

Expected number of infections

1.25

1.00

0.75

0.50

0.25
Expected number of infections

\section{5}

1.0

0.5

Expected number of infections

\section{0}

1.5

1.0

0.5

Supplementary Figure 2: Next-generation matrices for variable susceptibility (top), proportionate mixing (middle), and census-informed assortativity (bottom) models fitted to NYC seroprevalence data. Each column corresponds to an infected individual from a given demographic group and lists the expected number of secondary infections by group across the rows. Group A denotes non-Hispanic whites, B denotes Hispanics or Latinos, $\mathrm{C}$ denotes non-Hispanic African-Americans, $\mathrm{D}$ denotes non-Hispanic Asians, and $\mathrm{E}$ denotes multiracial or other demographic groups. 
medRxiv preprint doi: https://doi.org/10.1101/2021.01.15.21249881; this version posted May 1, 2021. The copyright holder for this preprint (which was not certified by peer review) is the author/funder, who has granted medRxiv a license to display the preprint in perpetuity.

It is made available under a CC-BY-NC-ND 4.0 International license .

463

464
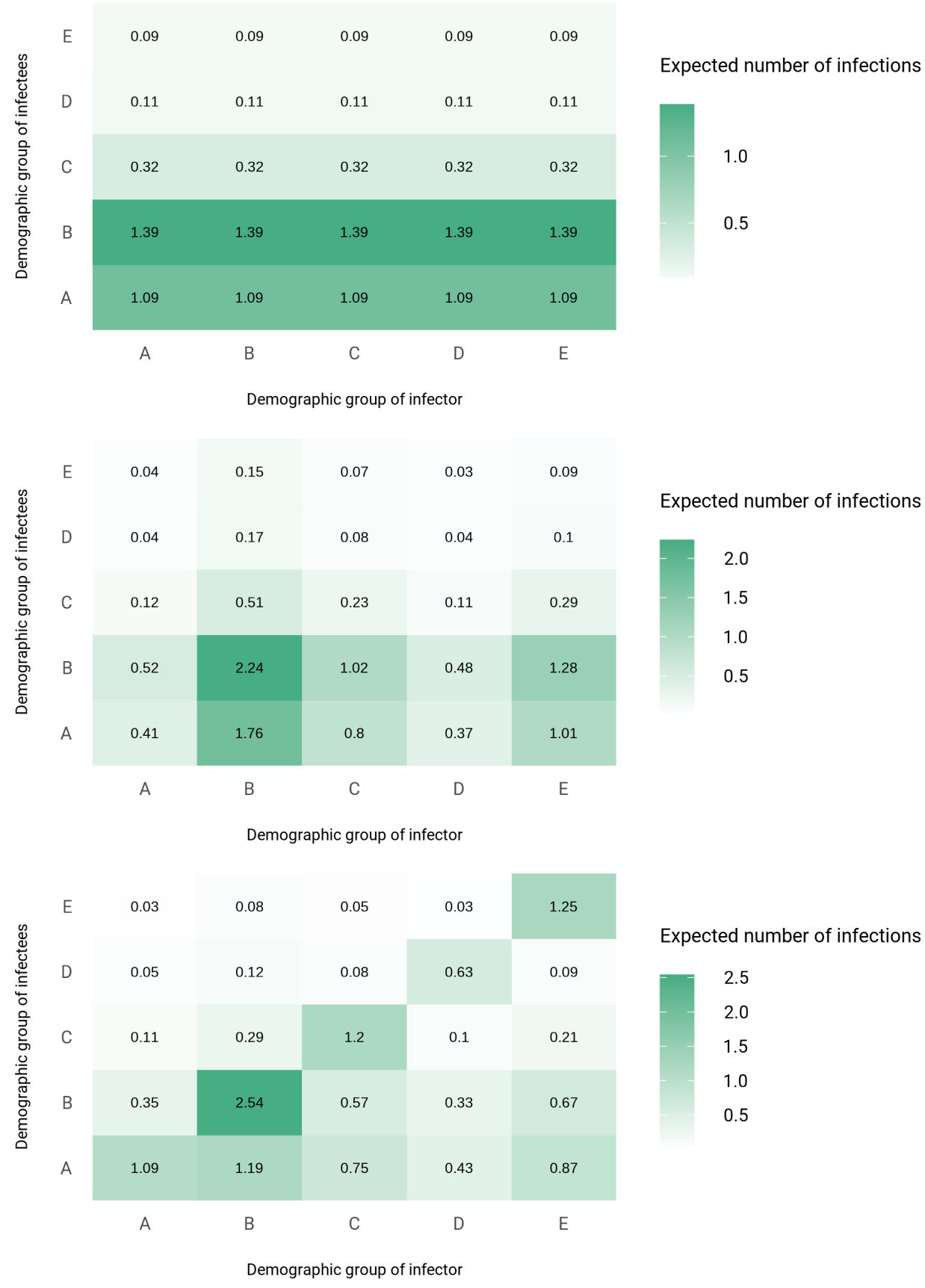

Supplementary Figure 3: Next-generation matrices for variable susceptibility (top), proportionate mixing (middle), and census-informed assortativity (bottom) models fitted to Long Island seroprevalence data. Each column corresponds to an infected individual from a given demographic group and lists the expected number of secondary infections by group across the rows. Group A denotes non-Hispanic whites, $B$ denotes Hispanics or Latinos, $C$ denotes non-Hispanic African-Americans, D denotes non-Hispanic Asians, and E denotes multiracial or other demographic groups.
Expected number of infections

2.0

1.5

1.0

0.5
Expected number of infections 


\section{Gamma approximation for HITs}

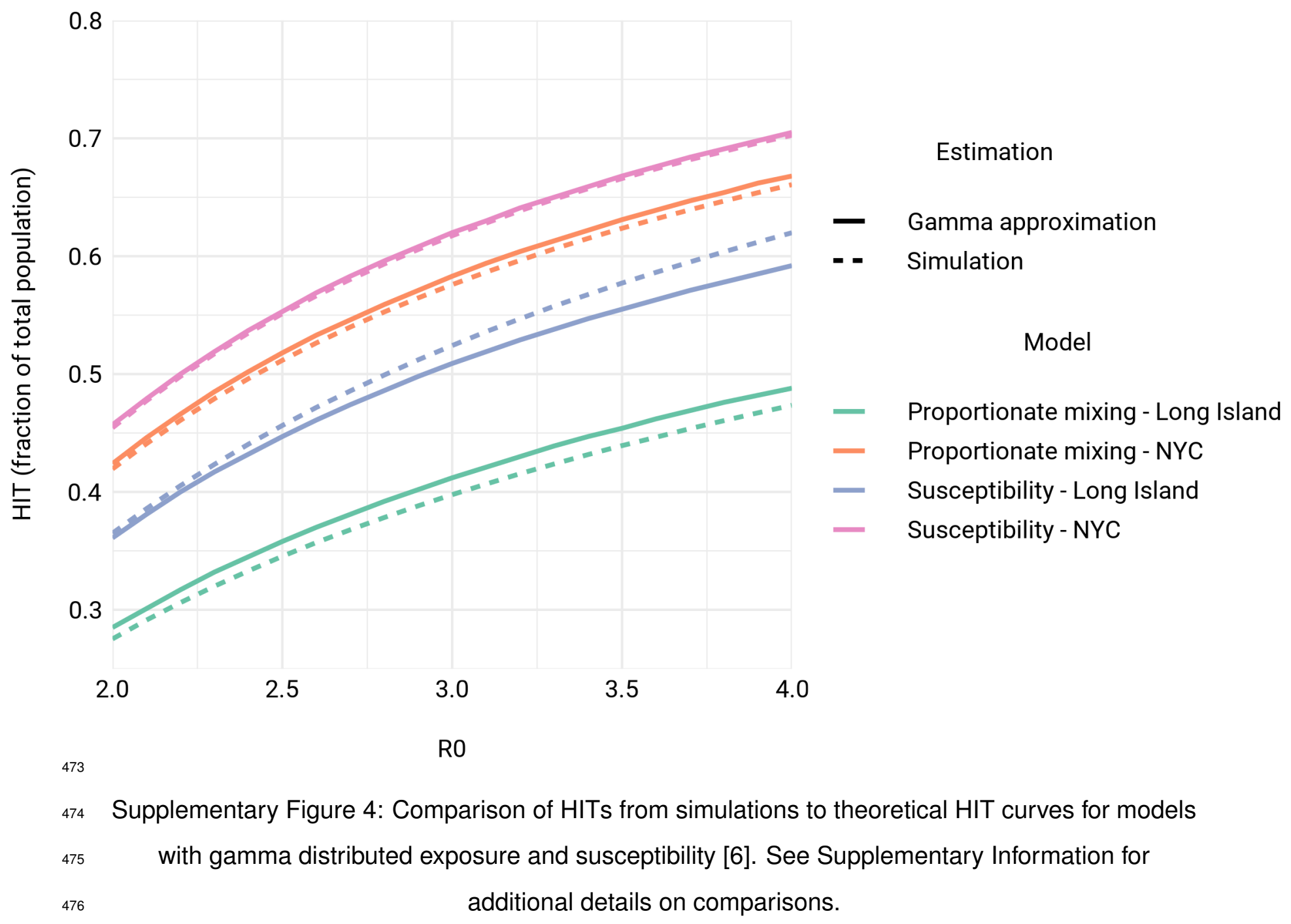



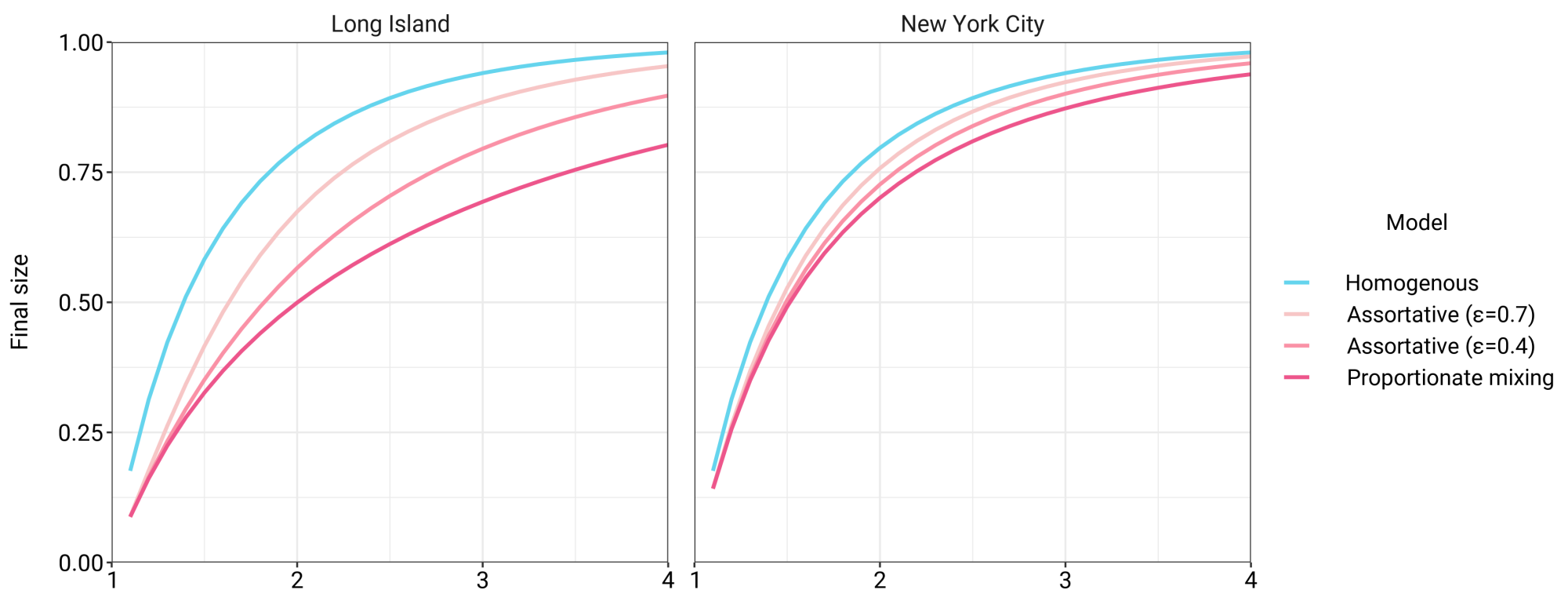

477

R0

$478 \quad$ Supplementary Figure 5: Incorporating assortativity in variable exposure models results in increased final epidemic sizes across a range of $R_{0}$ values. Variable exposure models were fitted to 


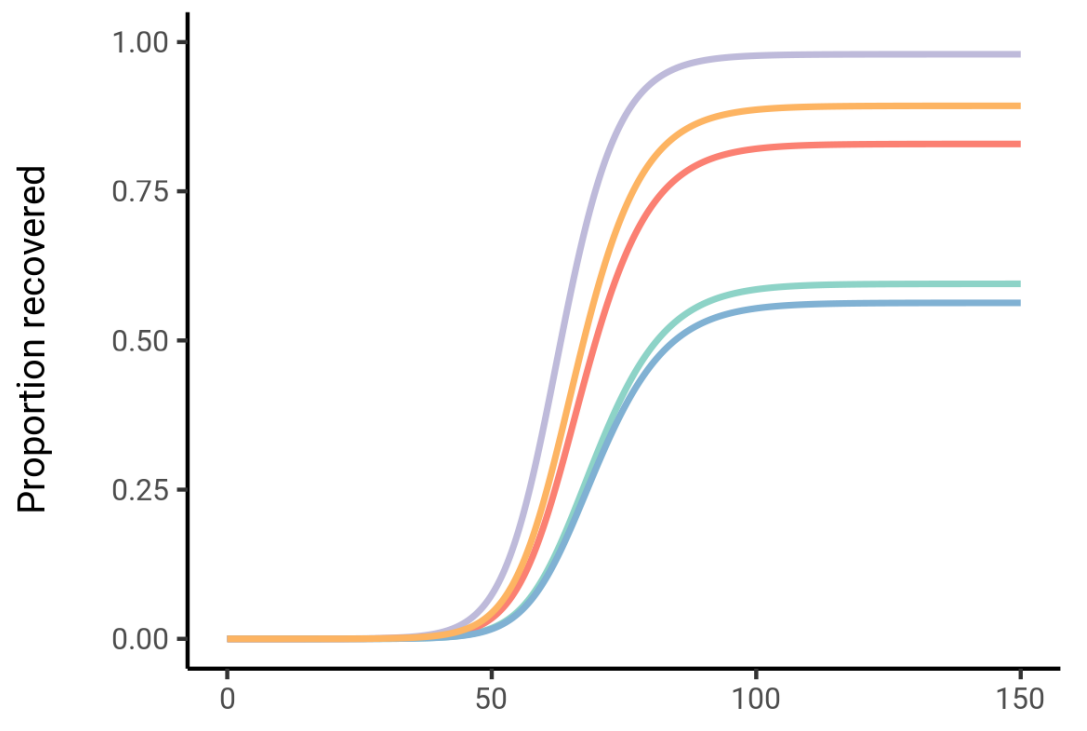

Days

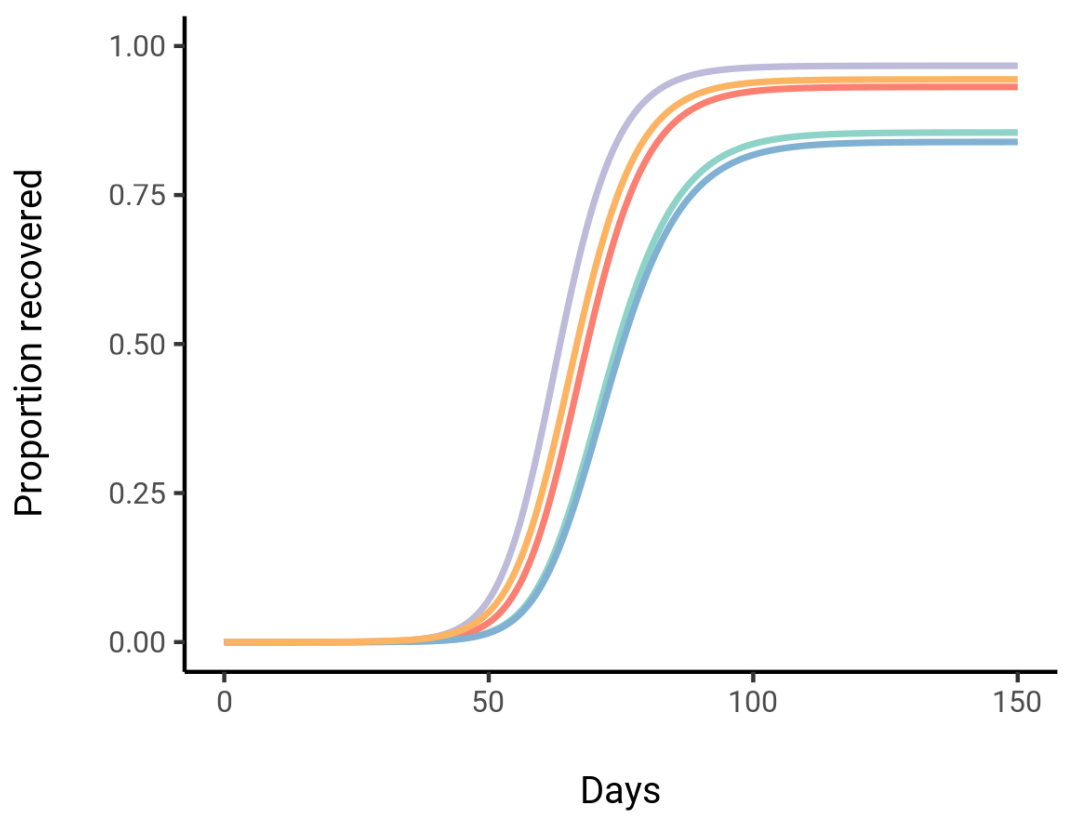

Racial and ethnic groups

- NH white

- Hispanic or Latino

- NH Black / African-American

NH Asian

Multiracial / other

Racial and ethnic groups
NH white
- Hispanic or Latino
- NH Black / African-American
- NH Asian

Multiracial / other

Supplementary Figure 6: Comparison of cumulative incidence trajectories for proportionate mixing (top) and assortative mixing ( $\epsilon=0.7$; bottom) models fitted to Long Island seroprevalence data. 


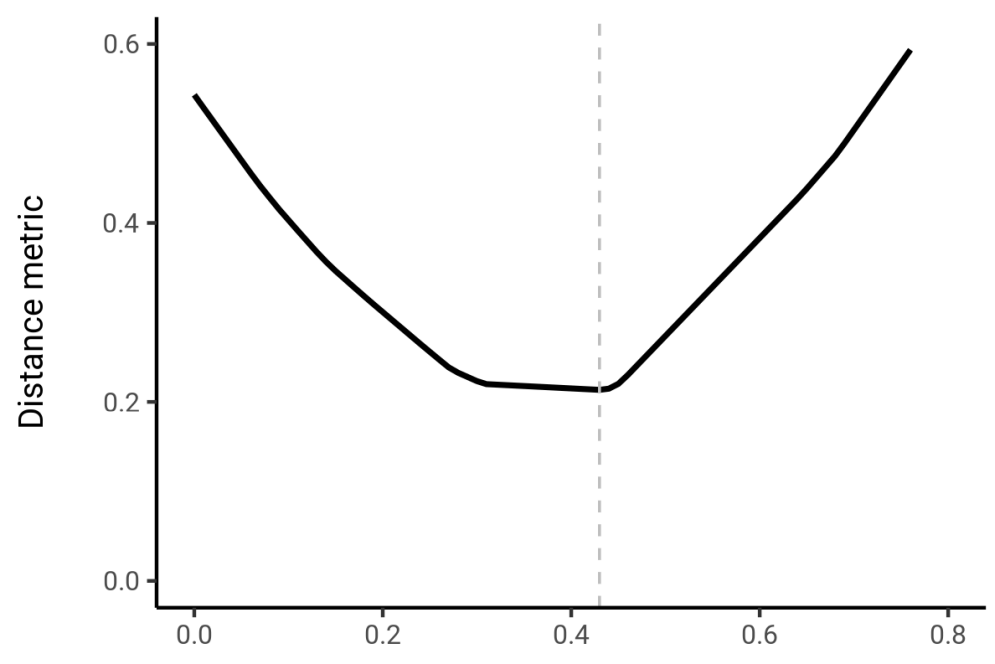

epsilon
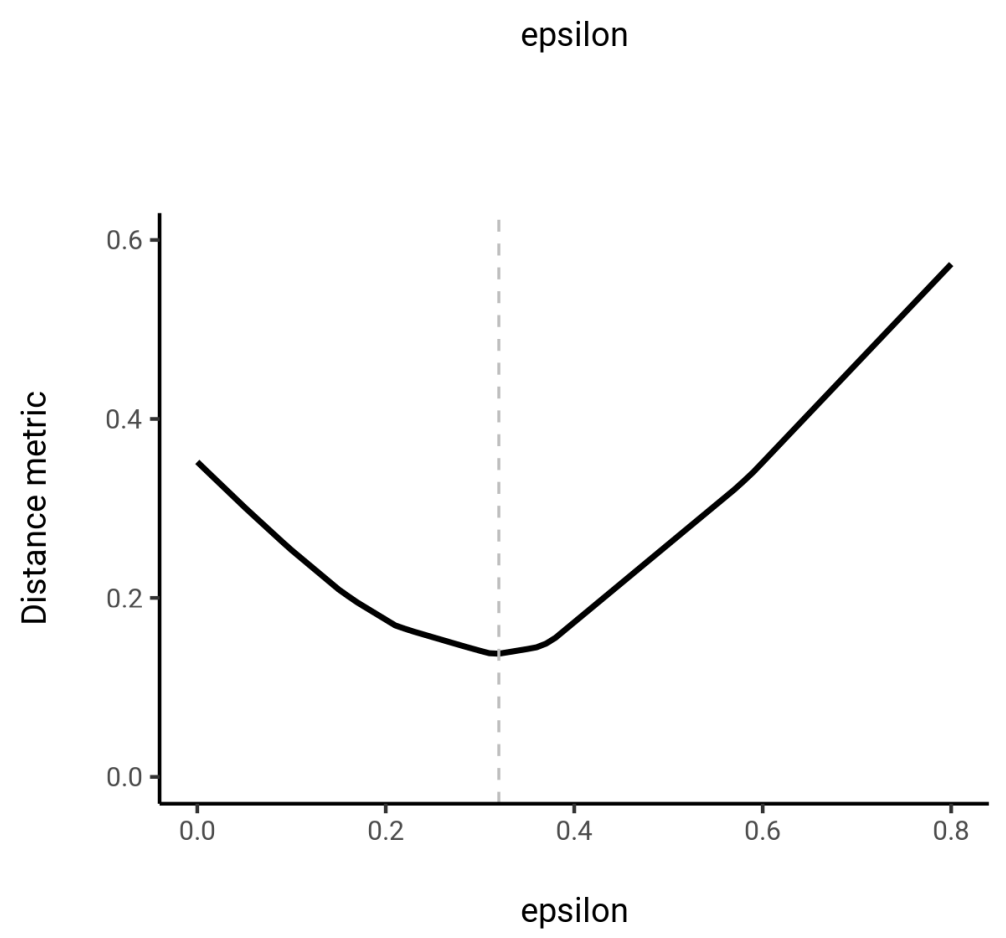

Supplementary Figure 7: First iteration of fitting $\epsilon$ in social contact matrices to census data for NYC (top) and Long Island (bottom). Distance metric denotes the $\sum_{i j}\left|C_{i j}-C^{\prime} i j\right|$ (see methods) scaled by $\sum C_{i j}$; this represents the number of "mismatched" contacts relative to the total number of contacts. 
493

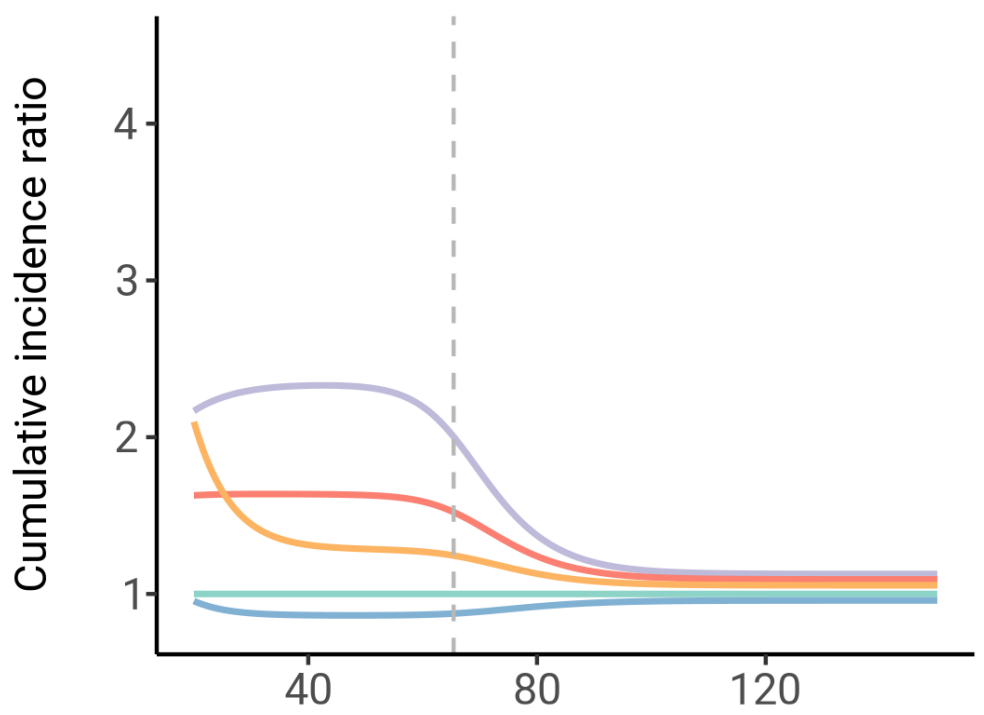

Days

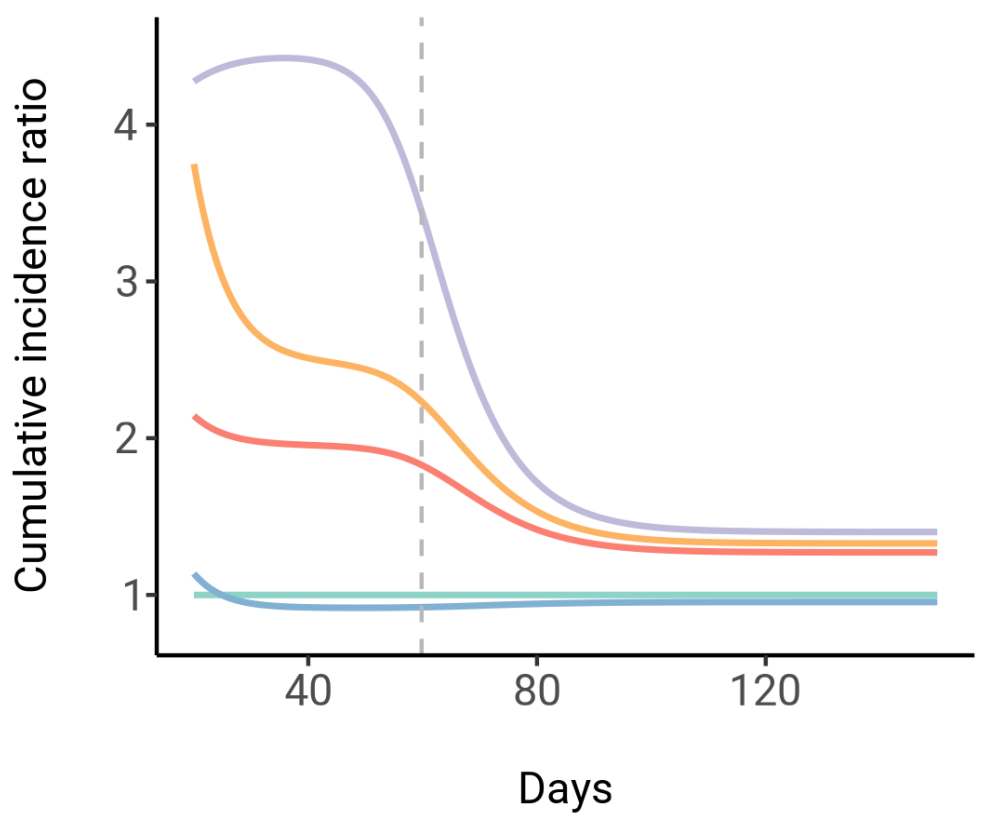

Racial and ethnic groups

Racial and ethnic groups

$\mathrm{NH}$ white

Hispanic or Latino

NH Black / African-American

$\mathrm{NH}$ Asian

Multiracial / other

Supplementary Figure 8: Dynamics of cumulative incidence rate ratios relative to non-Hispanic whites in census-informed assortative mixing models, fitted to NYC (top) and Long Island (bottom) seroprevalence data. Dashed line represents the peak overall incidence for the epidemic. 
medRxiv preprint doi: https://doi.org/10.1101/2021.01.15.21249881; this version posted May 1, 2021. The copyright holder for this preprint (which was not certified by peer review) is the author/funder, who has granted medRxiv a license to display the preprint in perpetuity. It is made available under a CC-BY-NC-ND 4.0 International license .
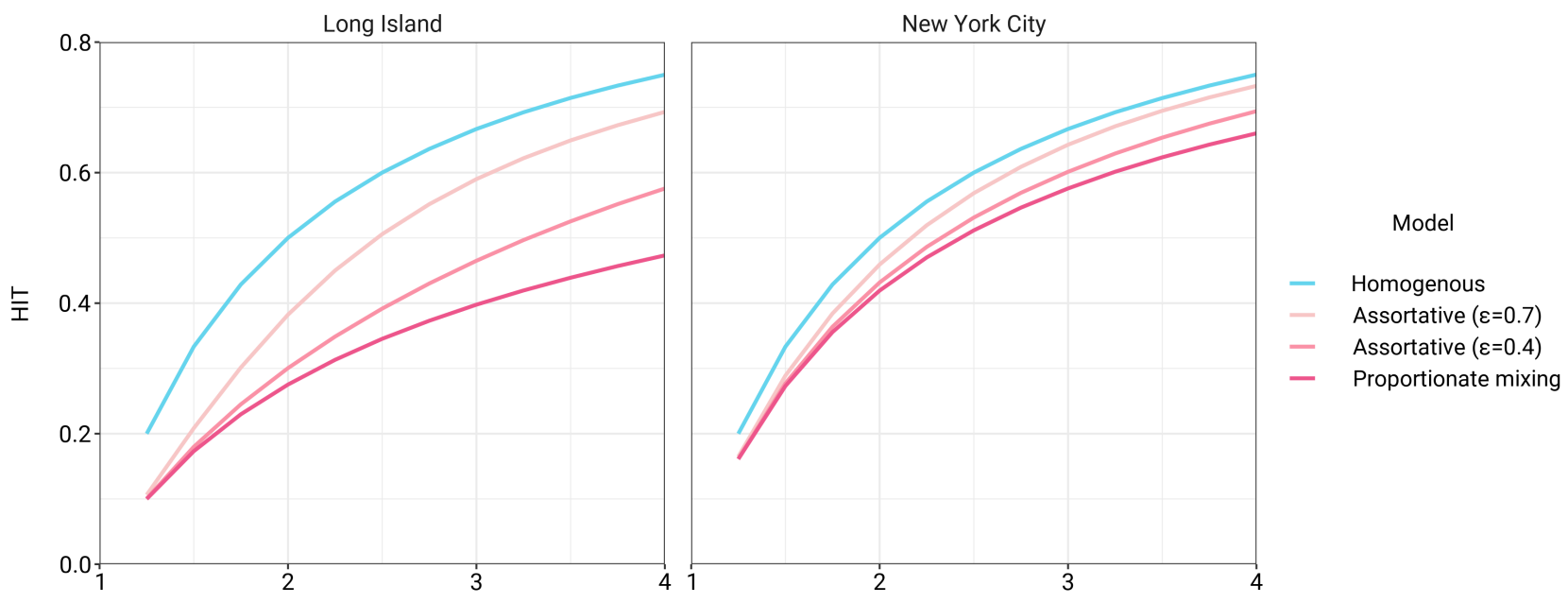

498

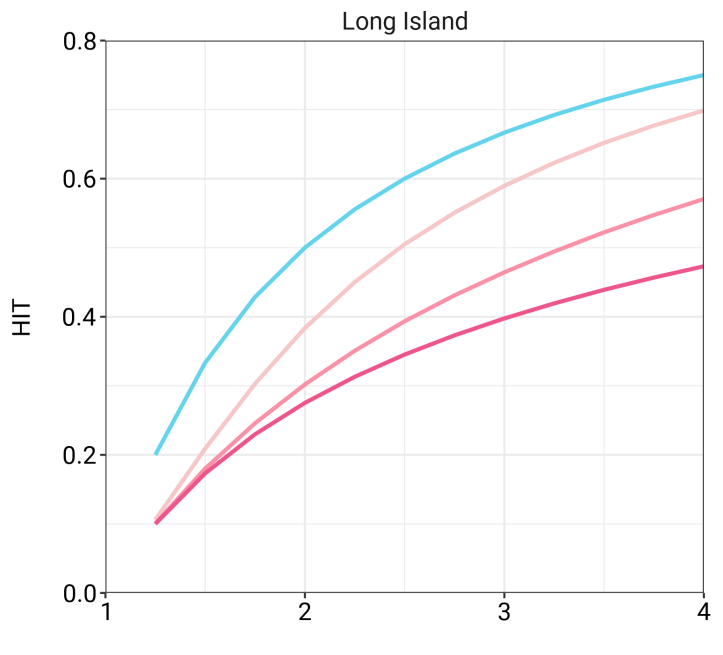

R0

Model

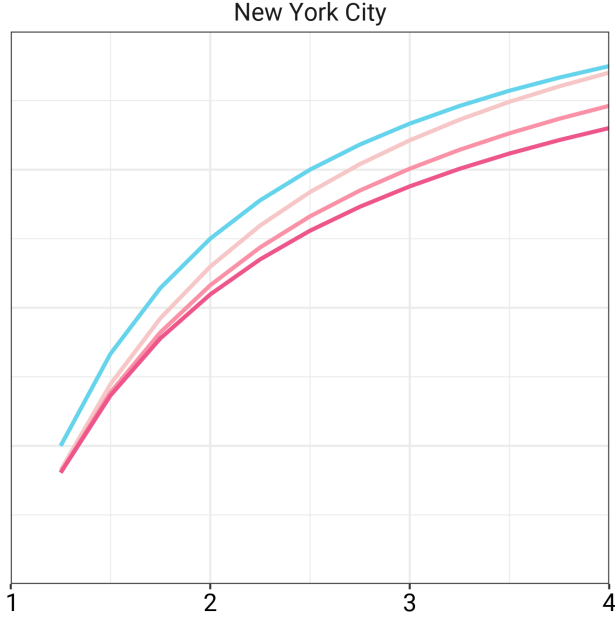

- Homogenous Assortative $(\varepsilon=0.7)$ Assortative $(\varepsilon=0.4)$

- Proportionate mixing

499

RO

Supplementary Figure 9: HITs versus $R_{0}$ in variable exposure models with mitigation measures for $\alpha=0.3$ (top) and $\alpha=0.6$ (bottom). NPIs were initiated when cumulative incidence reached $5 \%$ in all models and continued for 50 days. Models were fitted to NYC and Long Island serosurvey data. 
medRxiv preprint doi: https://doi.org/10.1101/2021.01.15.21249881; this version posted May 1, 2021. The copyright holder for this preprint (which was not certified by peer review) is the author/funder, who has granted medRxiv a license to display the preprint in perpetuity. It is made available under a CC-BY-NC-ND 4.0 International license .

503

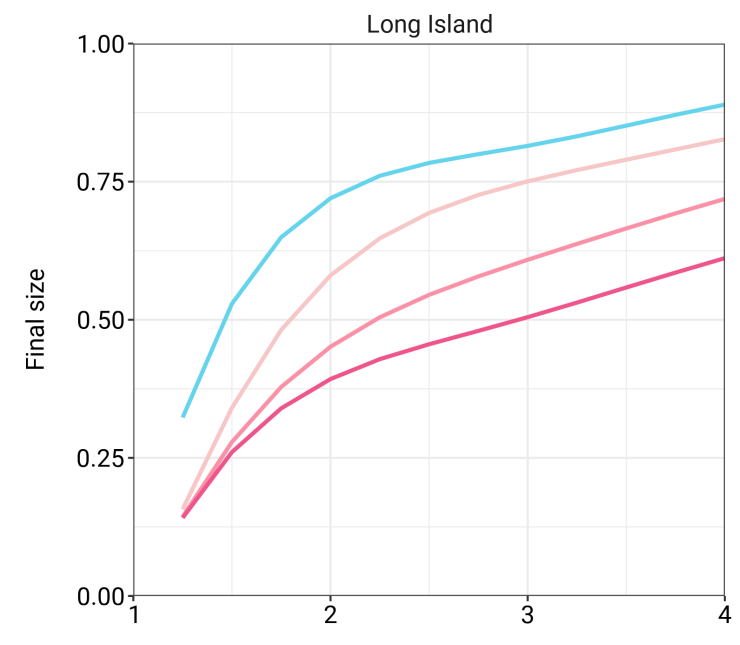

New York City

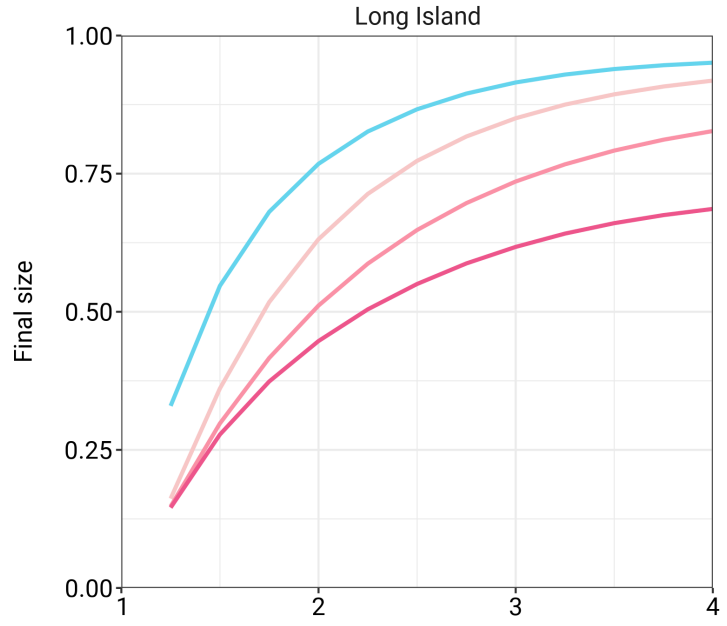

RO

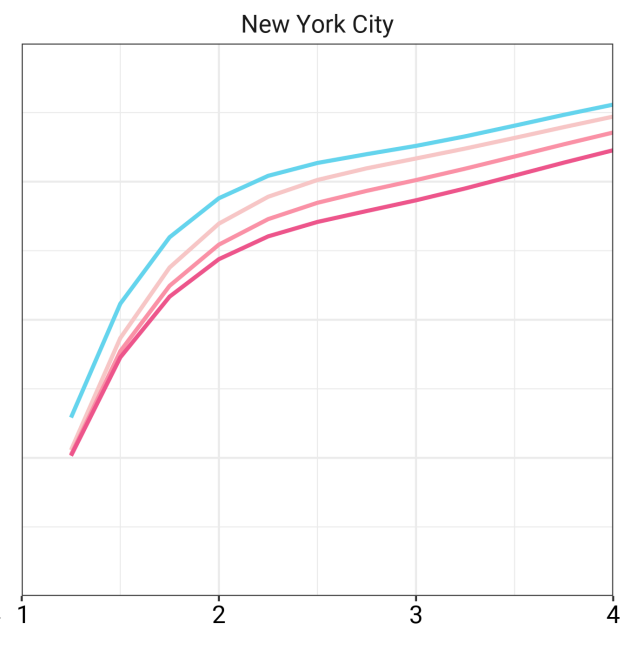

RO

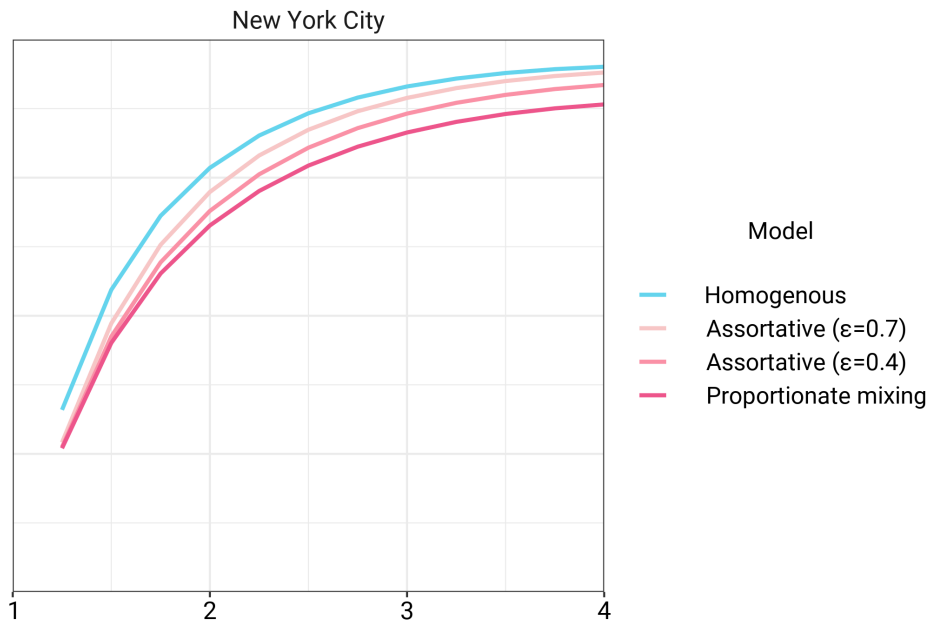

504

Supplementary Figure 10: Final epidemic sizes versus $R_{0}$ in variable exposure models with mitigation measures for $\alpha=0.3$ (top) and $\alpha=0.6$ (bottom). NPIs were initiated when cumulative incidence reached $5 \%$ in all models and continued for 50 days. Models were fitted to NYC and Long Island serosurvey data. 
medRxiv preprint doi: https://doi.org/10.1101/2021.01.15.21249881; this version posted May 1, 2021. The copyright holder for this preprint (which was not certified by peer review) is the author/funder, who has granted medRxiv a license to display the preprint in perpetuity.

It is made available under a CC-BY-NC-ND 4.0 International license .

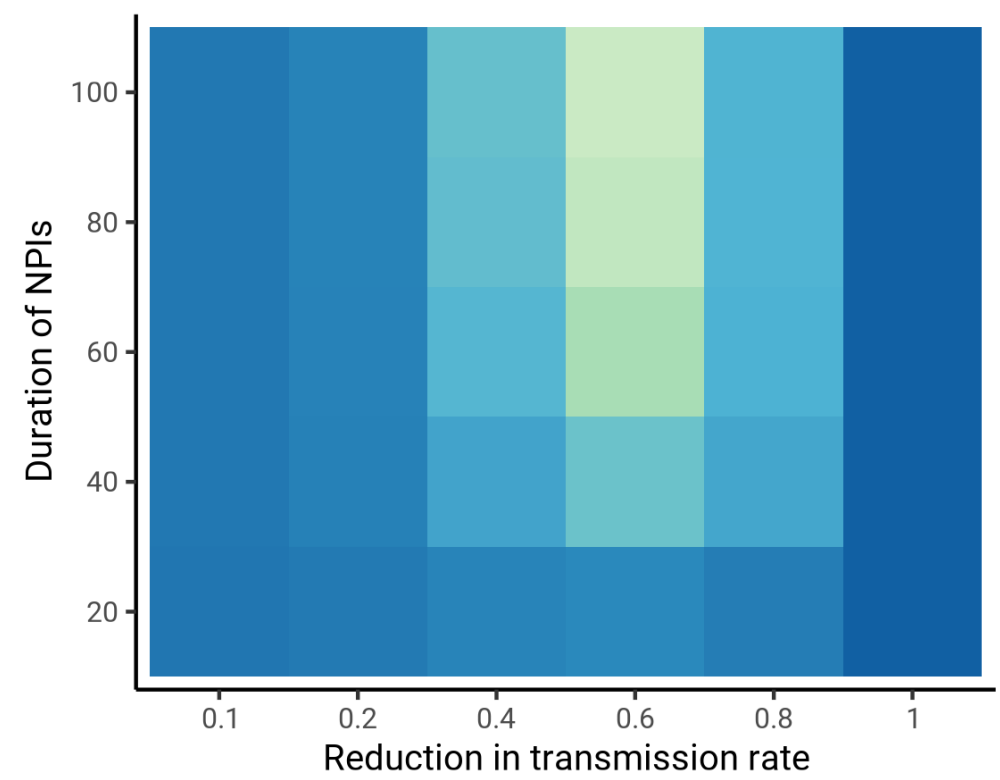

Final.size

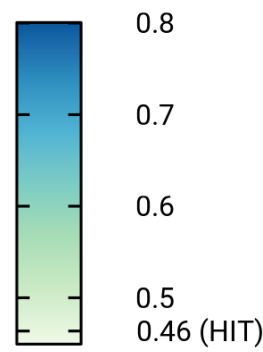

Supplementary Figure 11: Sensitivity analysis on the impact of intensity and duration of NPIs on final epidemic sizes. HIT values for the same mitigation parameters were $46.4 \pm 0.5 \%$ (range). The smallest final size, corresponding to $\alpha=0.6$ and duration $=100$, was $51 \%$. Census-informed assortativity models were fit to Long Island seroprevalence data. NPIs were initiated when cumulative incidence reached $5 \%$ in all models. 
medRxiv preprint doi: https://doi.org/10.1101/2021.01.15.21249881; this version posted May 1, 2021. The copyright holder for this preprint (which was not certified by peer review) is the author/funder, who has granted medRxiv a license to display the preprint in perpetuity. It is made available under a CC-BY-NC-ND 4.0 International license.

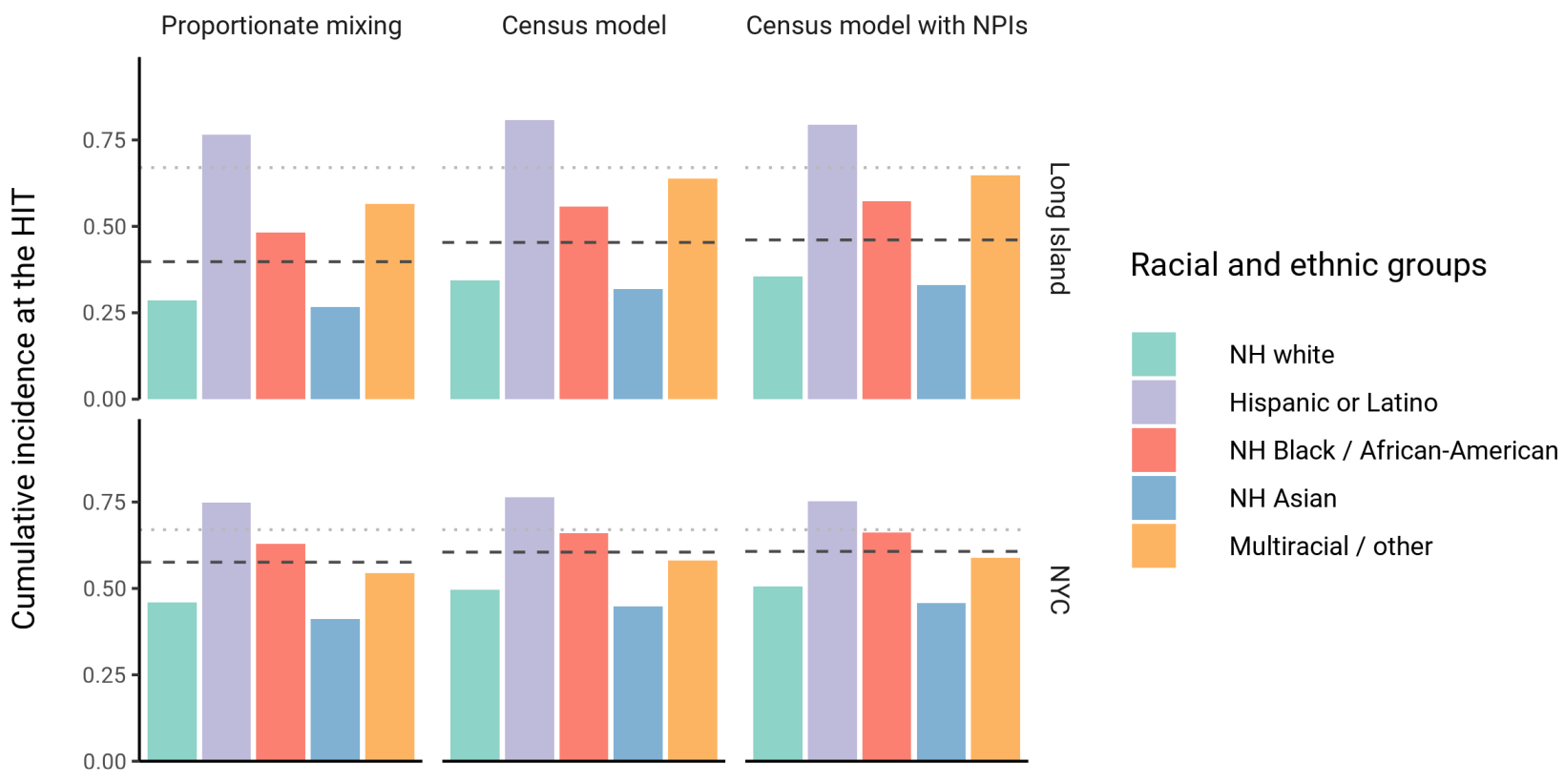

Supplementary Figure 12: Cumulative incidence is disproportionately higher in some racial and ethnic minorities when the overall HIT is reached across model types and locations. Results are shown for an epidemic with $R_{0}=3$, and NPIs were modeled with $\alpha=0.3$ for 50 days. The HIT for the population is indicated with a black line, and the HIT for a homogeneous model with the same $R_{0}$ is indicated with a gray line. 
$\alpha=0.3$

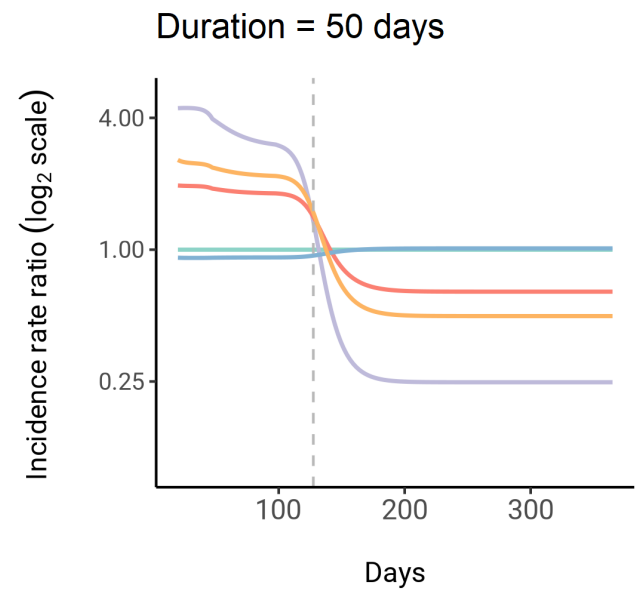

$\alpha=0.6$

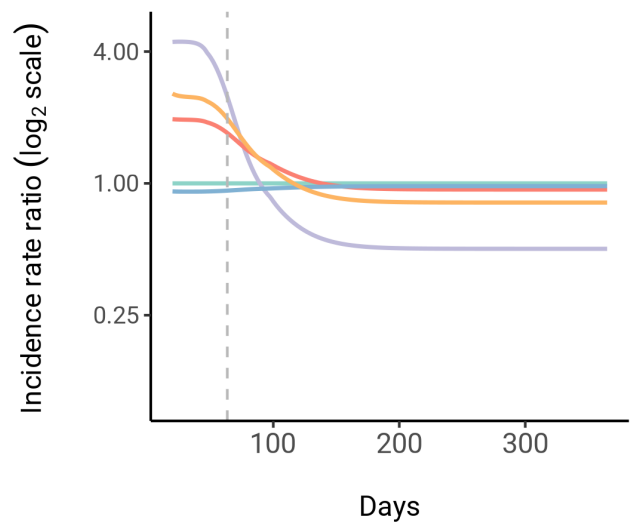

Duration $=100$ days
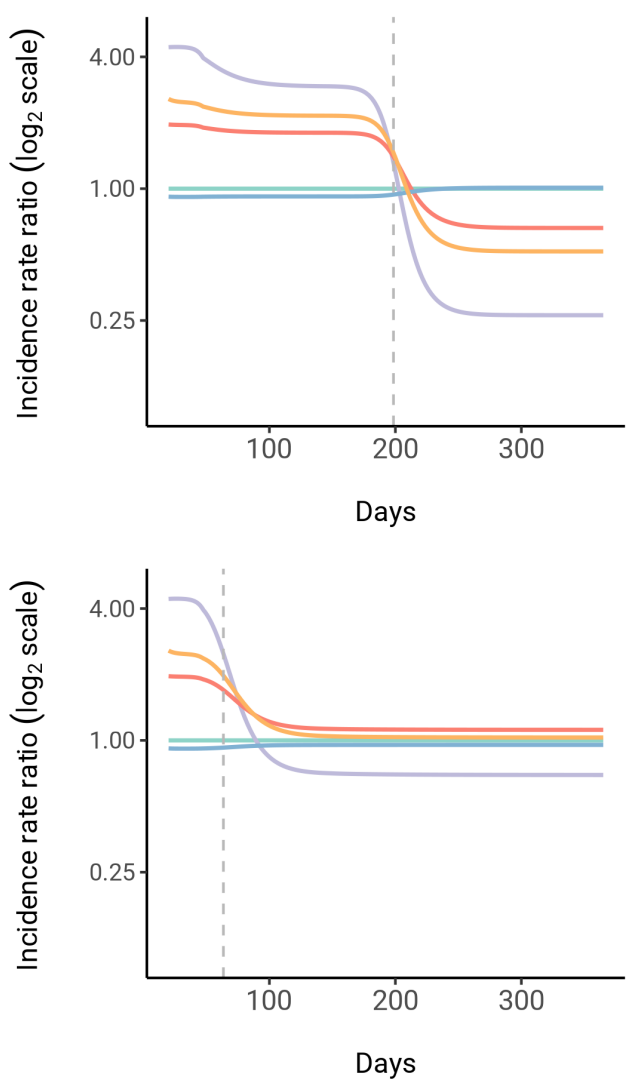

Racial and ethnic groups

- $\quad \mathrm{NH}$ white

- Hispanic or Latino

- NH Black / African-American

- NH Asian

- Multiracial / other

Racial and ethnic groups

- NH white

- Hispanic or Latino

- NH Black / African-American

- NH Asian

- Multiracial / other
521

Supplementary Figure 13: Dynamics of incidence rate ratios relative to non-Hispanic whites in census-informed assortative mixing models with mitigation measures. Four models were fit to Long Island seroprevalence data with varied NPI intensity and duration parameters as indicated. Dashed line represents the peak overall incidence for the epidemic. Results for no mitigation measures (i.e. $\alpha=1$ ) are shown in Figure 3. 
medRxiv preprint doi: https://doi.org/10.1101/2021.01.15.21249881; this version posted May 1, 2021. The copyright holder for this preprint (which was not certified by peer review) is the author/funder, who has granted medRxiv a license to display the preprint in perpetuity. It is made available under a CC-BY-NC-ND 4.0 International license .

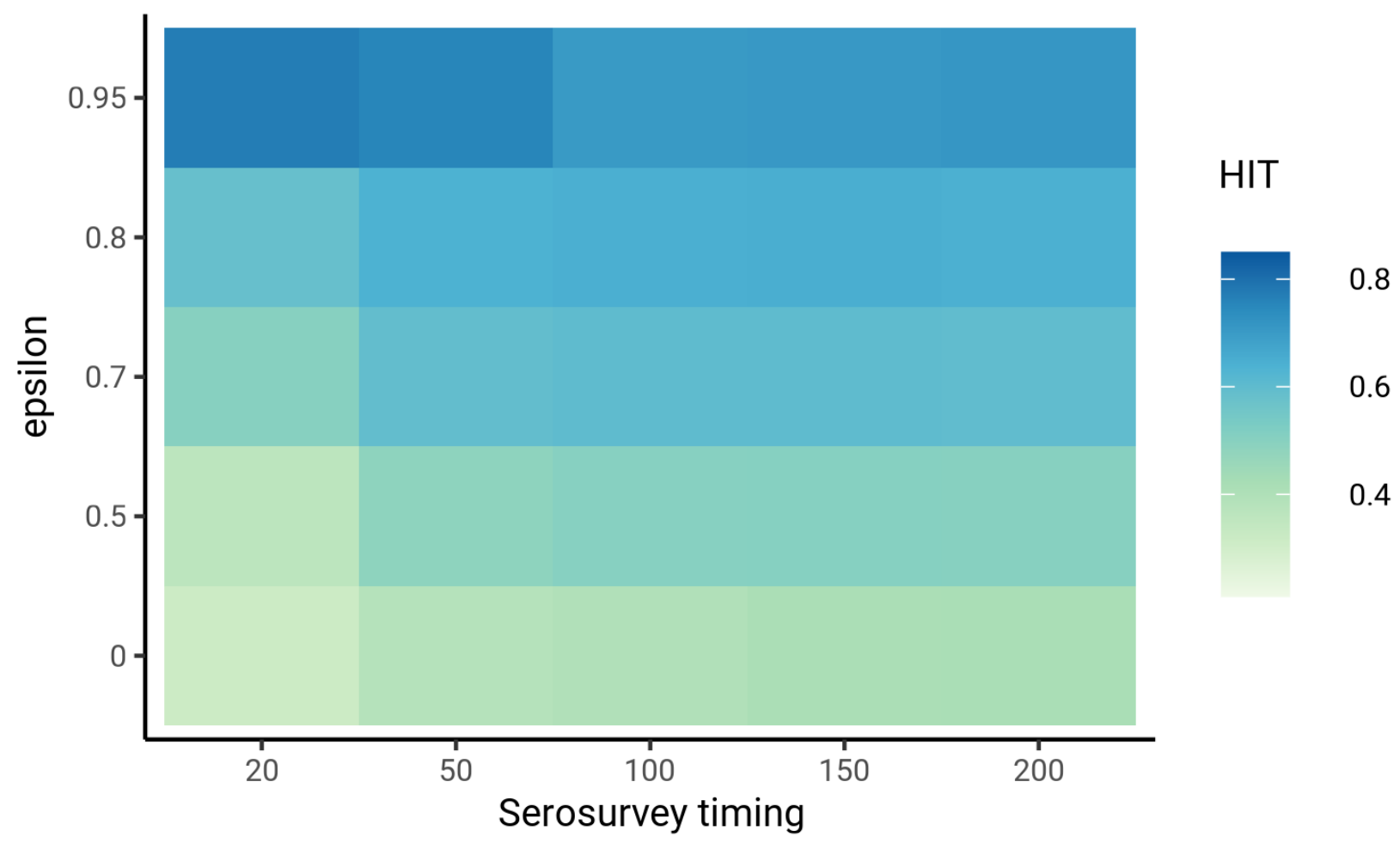

Supplementary Figure 14: Sensitivity analysis on timing of the serosurvey relative to the start of the epidemic. Models were fit to Long Island seroprevalence data. Varying the timing of epidemic start did not substantially affect HIT estimates, as long as the time between epidemic start and serosurvey was reasonable (e.g., $>20$ days) and assortativity was low $(\epsilon<0.8)$. 
medRxiv preprint doi: https://doi.org/10.1101/2021.01.15.21249881; this version posted May 1, 2021. The copyright holder for this preprint (which was not certified by peer review) is the author/funder, who has granted medRxiv a license to display the preprint in perpetuity. It is made available under a CC-BY-NC-ND 4.0 International license .

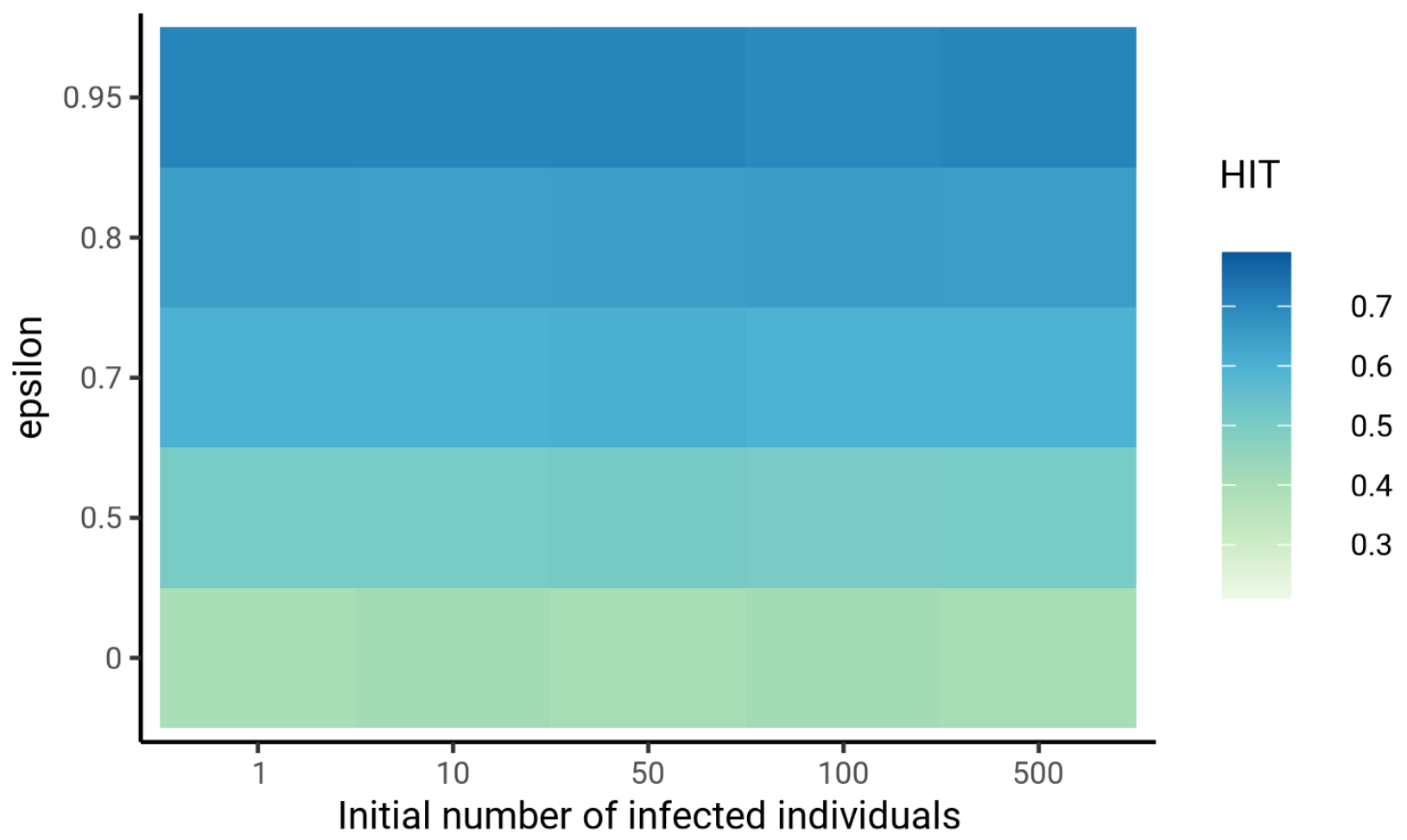

Supplementary Figure 15: Sensitivity analysis on initial number of infected individuals in each group. Models were fit to Long Island seroprevalence data. The number of initial infected individuals did not substantially affect HIT estimates for low levels of assortativity $(\epsilon<0.8)$. 
medRxiv preprint doi: https://doi.org/10.1101/2021.01.15.21249881; this version posted May 1, 2021. The copyright holder for this preprint (which was not certified by peer review) is the author/funder, who has granted medRxiv a license to display the preprint in perpetuity. It is made available under a CC-BY-NC-ND 4.0 International license.

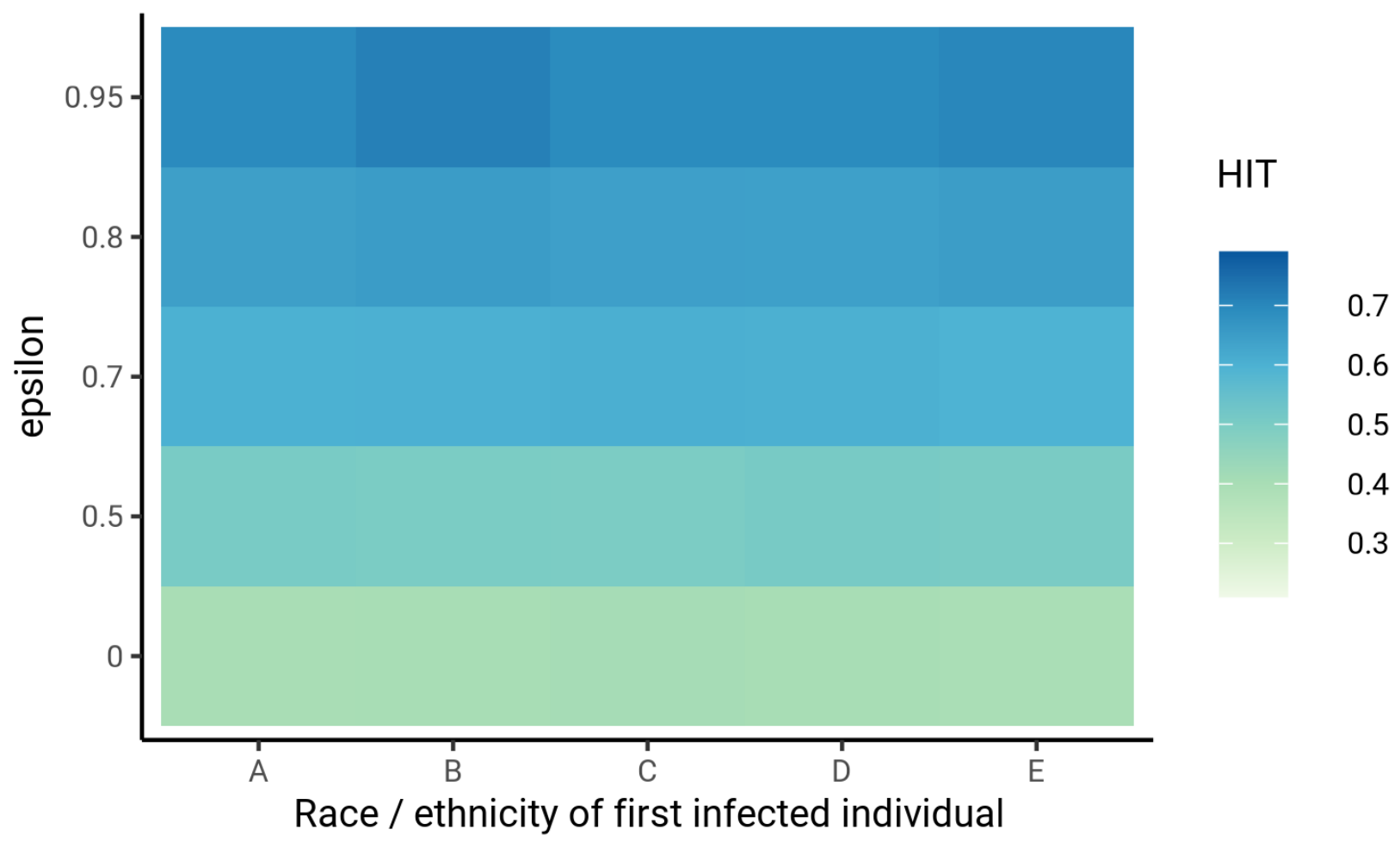

Supplementary Figure 16: Sensitivity analysis on race or ethnicity of first infected individual. Models were fit to Long Island seroprevalence data. The race or ethnicity of the first infected individual did not substantially affect HIT estimates for low levels of assortativity $(\epsilon<0.8)$. Group A denotes non-Hispanic whites, B denotes Hispanics or Latinos, C denotes non-Hispanic African-Americans, D denotes non-Hispanic Asians, and E denotes multiracial or other demographic groups. 


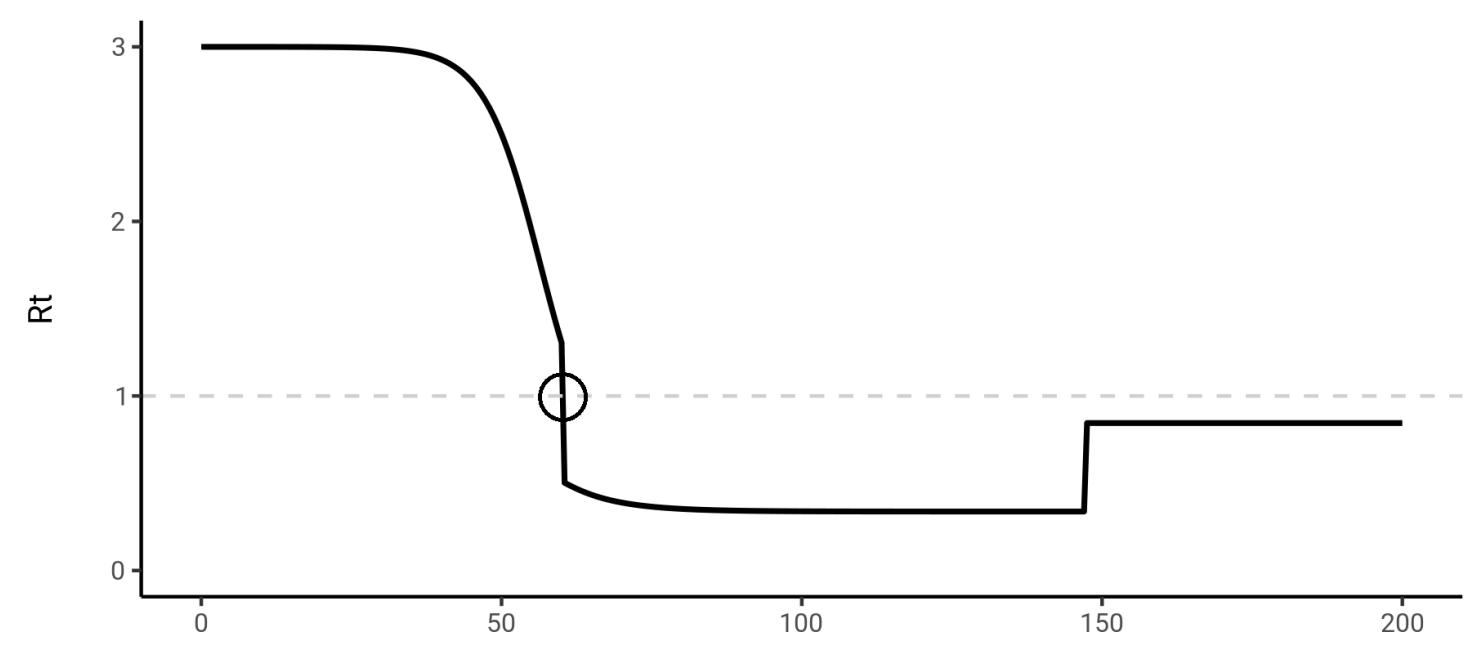

Days

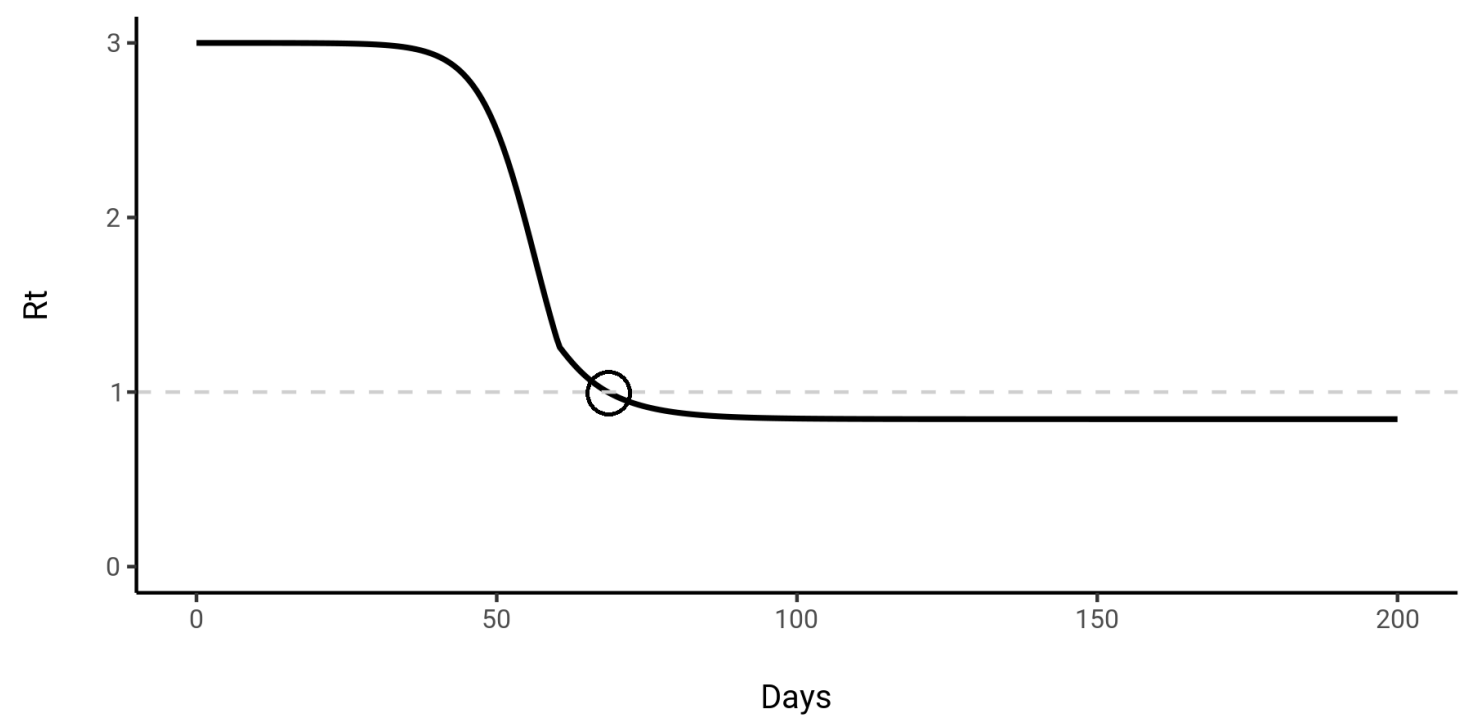

Supplementary Figure 17: $R_{t}$ calculation accounting for $\alpha$ (top) and without accounting for $\alpha$ (bottom) for a mitigated epidemic trajectory. The model was fit to Long Island census and serosurvey data, and mitigation was initiated on day 60 for 100 days with $\alpha=0.4$. The population reaches the HIT due to mitigation measures in the top $R_{t}$ trajectory at the circled time point and remains above the HIT after mitigation measures are lifted. However, we are defining the HIT relative to the unmitigated epidemic, which occurs when $R_{t}$ crosses 1 in the bottom trajectory at the circled time point. The interpretation is that even if all mitigation measures were lifted at this point, the unmitigated population will still have reached the HIT. 
551

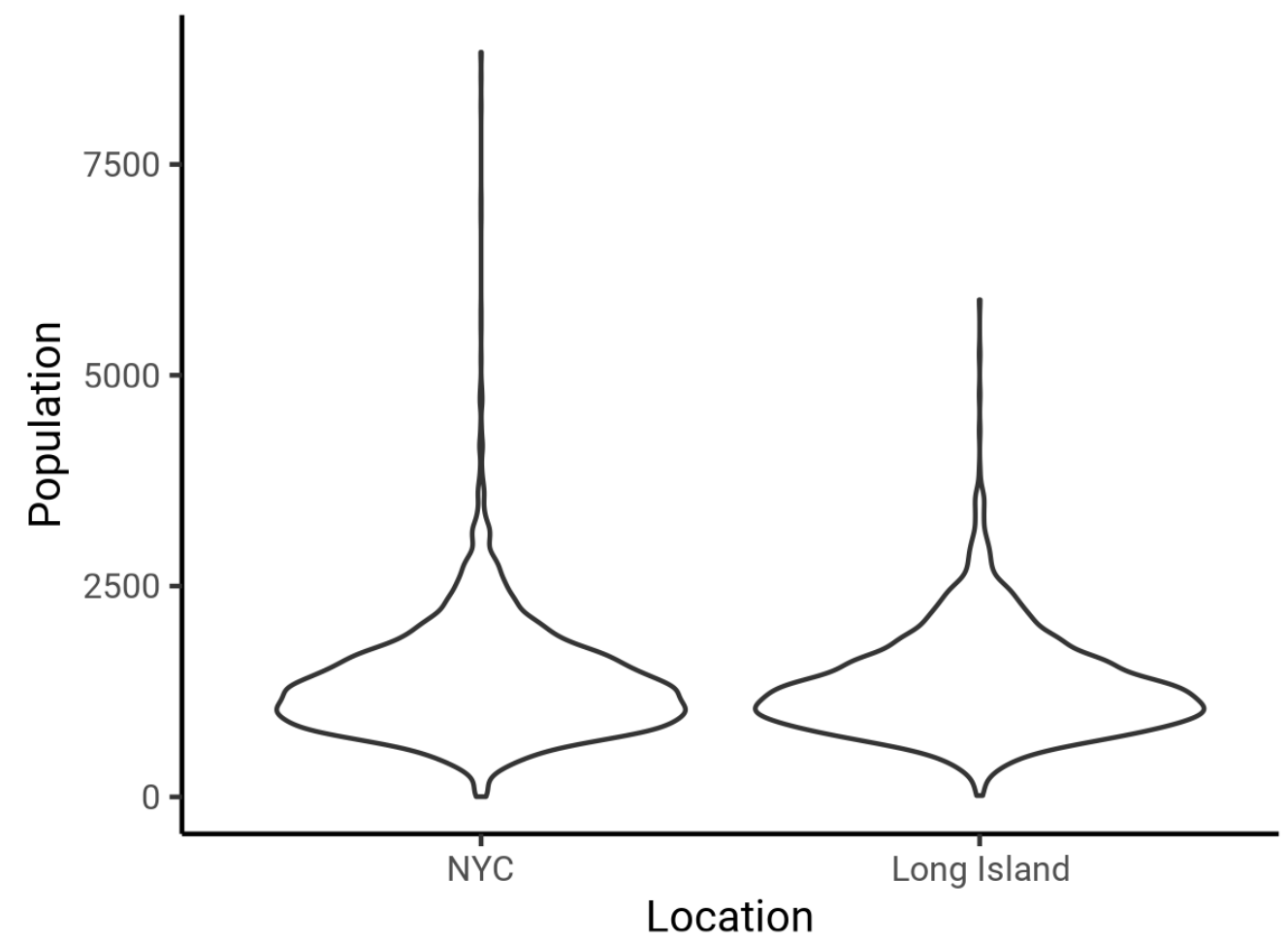

Supplementary Figure 18: Distribution of census block group sizes in NYC (left) and Long Island. The mean and S.D. of the population size was $1357 \pm 649$ for NYC and $1331 \pm 590$ for Long Island, suggesting that these block groups roughly correspond to local neighborhoods. 
555

A B $\quad$ C $\quad$ D $\quad$ E
A 0.616
0.178
0.101
$0.298 \quad 0.284$
B 0.161
0.509
0.24
$0.213 \quad 0.236$
C 0.069
0.188
0.572
$0.078 \quad 0.215$
D 0.128
0.1010 .049
0.375
0.164
E $\quad 0.026$
$0.024 \quad 0.029$
0.035
0.102

Supplementary Table 1: Exposure index matrix for NYC. From the perspective of an individual from column $j$, each row gives the proportion of people in an average neighborhood that are from demographic group $i$. Group A denotes non-Hispanic whites, B denotes Hispanics or Latinos, C denotes non-Hispanic African-Americans, D denotes non-Hispanic Asians, and E denotes multiracial or other demographic groups.

$\begin{array}{llllll} & \text { A } & \text { B } & \text { C } & \text { D } & \text { E } \\ \text { A } & 0.770 & 0.432 & 0.269 & 0.570 & 0.532 \\ \text { B } & 0.119 & 0.358 & 0.278 & 0.130 & 0.189 \\ \text { C } & 0.038 & 0.142 & 0.378 & 0.067 & 0.126 \\ \text { D } & 0.056 & 0.047 & 0.047 & 0.208 & 0.080 \\ \text { E } & 0.017 & 0.022 & 0.028 & 0.026 & 0.073\end{array}$

Supplementary Table 2: Exposure index matrix for Long Island. From the perspective of an individual from column $j$, each row gives the proportion of people in an average neighborhood that are from demographic group $i$. Group A denotes non-Hispanic whites, B denotes Hispanics or Latinos, C denotes non-Hispanic African-Americans, D denotes non-Hispanic Asians, and E denotes multiracial or other demographic groups. 
medRxiv preprint doi: https://doi.org/10.1101/2021.01.15.21249881; this version posted May 1, 2021. The copyright holder for this preprint (which was not certified by peer review) is the author/funder, who has granted medRxiv a license to display the preprint in perpetuity. It is made available under a CC-BY-NC-ND 4.0 International license.

$\begin{array}{llllll}\text { New York City } & \text { A } & \text { B } & \text { C } & \text { D } & \text { E } \\ \text { Proportionate mixing } & 1.00 & 2.25 & 1.62 & 0.86 & 1.28 \\ \text { Census model } & 1.00 & 1.62 & 1.35 & 0.90 & 1.17 \\ \text { Long Island } & \text { A } & \text { B } & \text { C } & \text { D } & \text { E } \\ \text { Proportionate mixing } & 1.00 & 4.31 & 1.96 & 0.92 & 2.48 \\ \text { Census model } & 1.00 & 2.60 & 1.63 & 0.93 & 1.90\end{array}$

Supplementary Table 3: Total contact rate ratios relative to non-Hispanic whites for proportionate mixing and census models fit to New York City (top) and Long Island (bottom) data. Group A denotes non-Hispanic whites, B denotes Hispanics or Latinos, $\mathrm{C}$ denotes non-Hispanic African-Americans, D denotes non-Hispanic Asians, and $\mathrm{E}$ denotes multiracial or other demographic groups. 


$\begin{array}{lllllll}\text { Iteration } & \epsilon & \mathrm{A} \text { (reference) } & \mathrm{B} & \mathrm{C} & \mathrm{D} & \mathrm{E} \\ 0 & 0.000 & 1 & 1.000 & 1.000 & 1.000 & 1.000 \\ 1 & 0.393 & 1 & 1.696 & 1.387 & 0.897 & 1.189 \\ 2 & 0.462 & 1 & 1.609 & 1.345 & 0.905 & 1.171 \\ 3 & 0.455 & 1 & 1.617 & 1.350 & 0.904 & 1.173 \\ 4 & 0.456 & 1 & 1.616 & 1.349 & 0.904 & 1.173 \\ 5 & 0.456 & 1 & 1.616 & 1.349 & 0.904 & 1.173\end{array}$

Supplementary Table 4: Iterative census model fitting results for New York City. A-E are activity levels relative to Group A. Group A denotes non-Hispanic whites, B denotes Hispanics or Latinos, C denotes non-Hispanic African-Americans, D denotes non-Hispanic Asians, and $E$ denotes multiracial or other demographic groups.

$\begin{array}{llllllll} & \text { Iteration } & \epsilon & \mathrm{A} \text { (reference) } & \mathrm{B} & \mathrm{C} & \mathrm{D} & \mathrm{E} \\ 0 & 0.000 & 1 & 1.000 & 1.000 & 1.000 & 1.000 \\ 1 & 0.307 & 1 & 2.906 & 1.704 & 0.929 & 2.021 \\ & & 0.400 & 1 & 2.546 & 1.615 & 0.934 & 1.873 \\ & 3 & 0.383 & 1 & 2.609 & 1.632 & 0.933 & 1.900 \\ 4 & 0.386 & 1 & 2.598 & 1.629 & 0.933 & 1.896 \\ & 5 & 0.386 & 1 & 2.598 & 1.629 & 0.933 & 1.896\end{array}$

Supplementary Table 5: Iterative census model fitting results for Long Island. A-E are activity levels relative to Group A. Group A denotes non-Hispanic whites, B denotes Hispanics or Latinos, C denotes non-Hispanic African-Americans, D denotes non-Hispanic Asians, and $E$ denotes multiracial or other demographic groups. 


\section{References}

[1] Randolph, H. E. \& Barreiro, L. B. Herd immunity: Understanding COVID-19. Immunity 52, 737-741 (2020).

[2] Hill, A. N. \& Longini, I. M., Jr. The critical vaccination fraction for heterogeneous epidemic models. Math. Biosci. 181, 85-106 (2003).

[3] Britton, T., Ball, F. \& Trapman, P. A mathematical model reveals the influence of population heterogeneity on herd immunity to SARS-CoV-2. Science 369, 846-849 (2020).

[4] Gomes, M. G. M. et al. Individual variation in susceptibility or exposure to SARS-CoV-2 lowers the herd immunity threshold. medRxiv (2020).

[5] Aguas, R. et al. Herd immunity thresholds for SARS-CoV-2 estimated from unfolding epidemics. medRxiv 2020.07.23.20160762 (2020).

[6] Tkachenko, A. V. et al. Persistent heterogeneity not short-term overdispersion determines herd immunity to COVID-19 (2020). 2008.08142.

[7] Metcalf, C. J. E., Viboud, C., Spiro, D. J. \& Grenfell, B. T. Using serology with models to clarify the trajectory of the SARS-CoV-2 emerging outbreak. Trends Immunol. 41, 849-851 (2020).

[8] Wallinga, J., van Boven, M. \& Lipsitch, M. Optimizing infectious disease interventions during an emerging epidemic. Proc. Natl. Acad. Sci. U. S. A. 107, 923-928 (2010).

[9] Bubar, K. M. et al. Model-informed COVID-19 vaccine prioritization strategies by age and serostatus (2020).

[10] Davies, N. G. et al. Age-dependent effects in the transmission and control of COVID-19 epidemics. Nat. Med. 26, 1205-1211 (2020).

[11] Miller, I. F., Becker, A. D., Grenfell, B. T. \& Metcalf, C. J. E. Disease and healthcare burden of COVID-19 in the united states. Nat. Med. 26, 1212-1217 (2020).

[12] Mossong, J. et al. Social contacts and mixing patterns relevant to the spread of infectious diseases. PLoS Med. 5, e74 (2008).

[13] Herzog, S. et al. Seroprevalence of IgG antibodies against SARS coronavirus 2 in belgium: a serial prospective cross-sectional nationwide study of residual samples. medRxiv 2020.06.08.20125179 (2020). 
medRxiv preprint doi: https://doi.org/10.1101/2021.01.15.21249881; this version posted May 1, 2021. The copyright holder for this preprint (which was not certified by peer review) is the author/funder, who has granted medRxiv a license to display the preprint in perpetuity. It is made available under a CC-BY-NC-ND 4.0 International license .

[14] Pollán, M. et al. Prevalence of SARS-CoV-2 in spain (ENE-COVID): a nationwide, populationbased seroepidemiological study. Lancet 396, 535-544 (2020).

[15] Shakiba, M. et al. Seroprevalence of COVID-19 virus infection in guilan province, iran. medRxiv 2020.04.26.20079244 (2020).

[16] Rosenberg, E. S. et al. Cumulative incidence and diagnosis of SARS-CoV-2 infection in new york. Ann. Epidemiol. 48, 23-29.e4 (2020).

[17] Hallal, P. et al. Remarkable variability in SARS-CoV-2 antibodies across brazilian regions: nationwide serological household survey in 27 states. medRxiv 2020.05.30.20117531 (2020).

[18] Chamie, G. et al. SARS-CoV-2 community transmission disproportionately affects latinx population during Shelter-in-Place in san francisco. Clin. Infect. Dis. (2020).

[19] Moore, J. T. et al. Disparities in incidence of COVID-19 among underrepresented Racial/Ethnic groups in counties identified as hotspots during june 5-18, 2020 - 22 states, February-June 2020. MMWR Morb. Mortal. Wkly. Rep. 69, 1122-1126 (2020).

[20] Millett, G. A. et al. Assessing differential impacts of COVID-19 on black communities. Ann. Epidemiol. 47, 37-44 (2020).

[21] Pan, D. et al. The impact of ethnicity on clinical outcomes in COVID-19: A systematic review. EClinicalMedicine 23, 100404 (2020).

[22] Chen, J. T. \& Krieger, N. Revealing the unequal burden of COVID-19 by income, race/ethnicity, and household crowding: US county vs ZIP code analyses. Harvard Center for Population and Development Studies Working Paper Series 19 (2020).

[23] Bassett, M. T., Chen, J. T. \& Krieger, N. Variation in racial/ethnic disparities in COVID-19 mortality by age in the united states: A cross-sectional study. PLoS Med. 17, e1003402 (2020).

[24] Hanage, W. P. et al. COVID-19: US federal accountability for entry, spread, and inequitieslessons for the future. Eur. J. Epidemiol. (2020).

[25] Chang, S. et al. Mobility network models of COVID-19 explain inequities and inform reopening. Nature (2020).

[26] Zelner, J. et al. Racial disparities in COVID-19 mortality are driven by unequal infection risks (2020). 
medRxiv preprint doi: https://doi.org/10.1101/2021.01.15.21249881; this version posted May 1, 2021. The copyright holder for this preprint (which was not certified by peer review) is the author/funder, who has granted medRxiv a license to display the preprint in perpetuity. It is made available under a CC-BY-NC-ND 4.0 International license .

[27] Kissler, S. M. et al. Reductions in commuting mobility correlate with geographic differences in SARS-CoV-2 prevalence in new york city. Nat. Commun. 11, 4674 (2020).

[28] Krieger, N., Testa, C., Hanage, W. P. \& Chen, J. T. US racial and ethnic data for COVID-19 cases: still missing in action. Lancet 396, e81 (2020).

[29] Nishiura, H., Linton, N. M. \& Akhmetzhanov, A. R. Serial interval of novel coronavirus (COVID19) infections. Int. J. Infect. Dis. 93, 284-286 (2020).

[30] Lauer, S. A. et al. The incubation period of coronavirus disease 2019 (COVID-19) from publicly reported confirmed cases: Estimation and application. Ann. Intern. Med. 172, 577-582 (2020).

[31] Wallinga, J., Kassteele, J. v. d. \& Hens, N. Contact patterns for contagious diseases. In Held, L., Hens, N., O’Neill, P. \& Wallinga, J. (eds.) Handbook of Infectious Disease Data Analysis, 93-110 (Chapman and Hall/CRC, 2019), 1 edn.

[32] Hethcote, H. W. Modeling heterogeneous mixing in infectious disease dynamics. In Models for Infectious Human Diseases: Their Structure and Relation to Data, 215-238 (Cambridge University Press, 1996).

[33] McCauley, C., Plummer, M., Moskalenko, S. \& Mordkoff, J. T. The exposure index: A measure of intergroup contact. Peace Confl. 7, 321-336 (2001).

[34] Richardson, E. T. et al. Reparations for black american descendants of persons enslaved in the U.S. and their estimated impact on SARS-CoV-2 transmission. medRxiv (2020).

[35] Henry Akintobi, T. et al. Community engagement of african americans in the era of COVID19: Considerations, challenges, implications, and recommendations for public health. Prev. Chronic Dis. 17, E83 (2020).

[36] Thakur, N., Lovinsky-Desir, S., Bime, C., Wisnivesky, J. P. \& Celedón, J. C. The structural and social determinants of the Racial/Ethnic disparities in the U.S. COVID-19 pandemic. what's our role? Am. J. Respir. Crit. Care Med. 202, 943-949 (2020).

[37] Tai, D. B. G., Shah, A., Doubeni, C. A., Sia, I. G. \& Wieland, M. L. The disproportionate impact of COVID-19 on racial and ethnic minorities in the united states. Clin. Infect. Dis. (2020).

[38] Khazanchi, R., Evans, C. T. \& Marcelin, J. R. Racism, not race, drives inequity across the COVID-19 continuum. JAMA Netw Open 3, e2019933 (2020). 
medRxiv preprint doi: https://doi.org/10.1101/2021.01.15.21249881; this version posted May 1, 2021. The copyright holder for this preprint (which was not certified by peer review) is the author/funder, who has granted medRxiv a license to display the preprint in perpetuity. It is made available under a CC-BY-NC-ND 4.0 International license .

[39] Krieger N, Testa C, Chen JT, Waterman PD, Hanage WP. A warning against using static US county-level community data to guide equity in COVID-19 vaccine distribution: Temporal and spatial correlations of community characteristics with COVID-19 cases and deaths vary enormously and are increasingly uninformative. HCPDS Working Paper 20 (2020).

[40] Van Dyke, M. E. et al. Racial and ethnic disparities in COVID-19 incidence by age, sex, and period among persons aged ¡25 years - 16 U.S. jurisdictions, january 1-december 31, 2020. MMWR Morb. Mortal. Wkly. Rep. 70, 382-388 (2021).

[41] Goldstein, E., Pitzer, V. E., O'Hagan, J. J. \& Lipsitch, M. Temporally varying relative risks for infectious diseases: Implications for infectious disease control. Epidemiology 28, 136-144 (2017).

[42] Koopman, J. S. et al. Assessing risk factors for transmission of infection. Am. J. Epidemiol. 133, 1199-1209 (1991).

[43] Kahn, R., Kennedy-Shaffer, L., Grad, Y. H., Robins, J. M. \& Lipsitch, M. Potential biases arising from epidemic dynamics in observational seroprotection studies. Am. J. Epidemiol. (2020).

[44] Neuwirth, C., Gruber, C. \& Murphy, T. Investigating duration and intensity of covid-19 socialdistancing strategies. Sci. Rep. 10, 20042 (2020).

[45] Handel, A., Longini, I. M., Jr \& Antia, R. What is the best control strategy for multiple infectious disease outbreaks? Proc. Biol. Sci. 274, 833-837 (2007).

[46] Millett, G. A. et al. White counties stand apart: The primacy of residential segregation in COVID-19 and HIV diagnoses. AIDS Patient Care STDS 34, 417-424 (2020).

[47] Boyd, R., Lindo, E., Weeks, L. \& McLemore, M. On racism: A new standard for publishing on racial health inequities. https://www .healthaffairs.org/do/10.1377/hblog20200630. 939347/full/. Accessed: 2020-11-27.

[48] Bailey, Z. D., Feldman, J. M. \& Bassett, M. T. How structural racism works - racist policies as a root cause of U.S. racial health inequities. N. Engl. J. Med. 384, 768-773 (2021).

[49] Blau, F. D., Koebe, J. \& Meyerhofer, P. A. Who are the essential and frontline workers? Tech. Rep. w27791, National Bureau of Economic Research (2020). 
medRxiv preprint doi: https://doi.org/10.1101/2021.01.15.21249881; this version posted May 1, 2021. The copyright holder for this preprint (which was not certified by peer review) is the author/funder, who has granted medRxiv a license to display the preprint in perpetuity. It is made available under a CC-BY-NC-ND 4.0 International license .

[50] Yang, T.-C., Emily Choi, S.-W. \& Sun, F. COVID-19 cases in US counties: roles of racial/ethnic density and residential segregation. Ethn. Health 1-11 (2020).

[51] Benfer, E. A. et al. Eviction, health inequity, and the spread of COVID-19: Housing policy as a primary pandemic mitigation strategy (2020).

[52] Mulberry, N., Tupper, P., Kirwin, E., McCabe, C. \& Colijn, C. Vaccine rollout strategies: The case for vaccinating essential workers early (2021).

[53] Wrigley-Field, E. et al. Geographically-targeted COVID-19 vaccination is more equitable than age-based thresholds alone. medRxiv (2021).

[54] Schmidt, H., Gostin, L. O. \& Williams, M. A. Is it lawful and ethical to prioritize racial minorities for COVID-19 vaccines? JAMA 324, 2023-2024 (2020).

[55] Clapham, H. et al. Seroepidemiologic study designs for determining SARS-COV-2 transmission and immunity. Emerg. Infect. Dis. 26, 1978-1986 (2020).

[56] Accorsi, E. K. et al. How to detect and reduce potential sources of biases in studies of SARSCoV-2 and COVID-19. Eur. J. Epidemiol. 36, 179-196 (2021).

[57] Kishore, N. et al. Lockdown related travel behavior undermines the containment of SARS-CoV$2(2020)$.

[58] Larremore, D. B. et al. Estimating SARS-CoV-2 seroprevalence and epidemiological parameters with uncertainty from serological surveys (2020).

[59] Feehan, D. \& Mahmud, A. Quantifying population contact patterns in the united states during the COVID-19 pandemic (2020).

[60] Kishore, N. et al. Measuring mobility to monitor travel and physical distancing interventions: a common framework for mobile phone data analysis. Lancet Digit Health 2, e622-e628 (2020).

[61] Flannery, D. D. et al. SARS-CoV-2 seroprevalence among parturient women in philadelphia. Sci Immunol 5 (2020).

[62] Chan, P. A. et al. Seroprevalence of SARS-CoV-2 antibodies in rhode island from a statewide random sample. Am. J. Public Health 111, 700-703 (2021). 